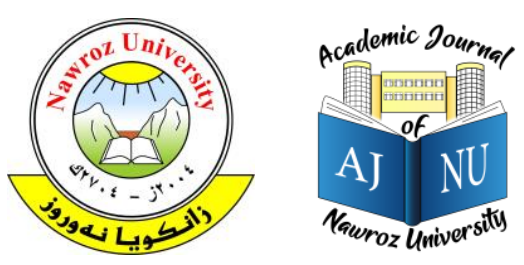

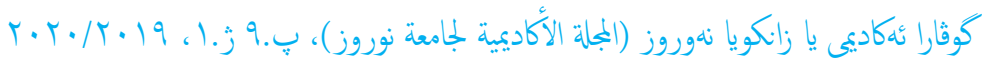

حقوق الطبع والنشر ؟2017. هذه مقالة الوصول اليها مفتوح موزعة تحت رخصة

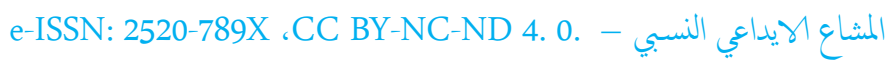

https://doi.org/10.25007/ajnu.v9n3a843

\title{
الآثار الاقتصادية لبعض متغيرات الاقتصاد الكلي على البطالة في العراق للفترة (2003-2017): دراسة قياسية
}

\author{
البحث مستل من اطروحة الدكتوراه للباحث الوول

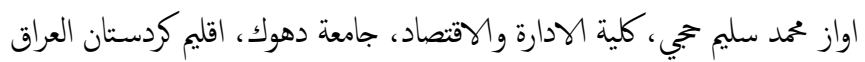

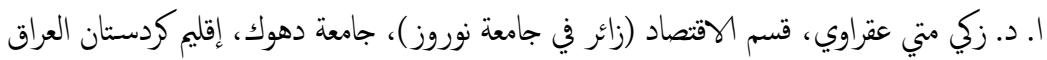

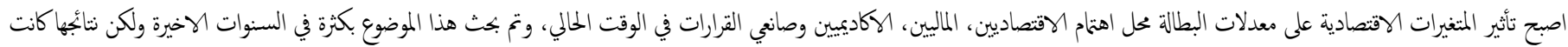

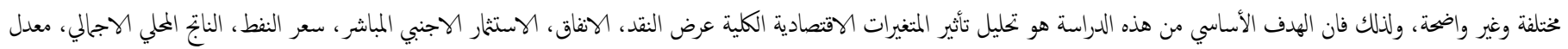

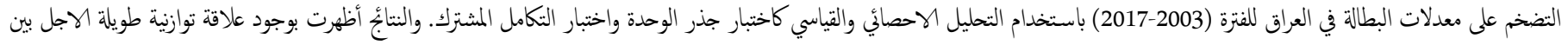

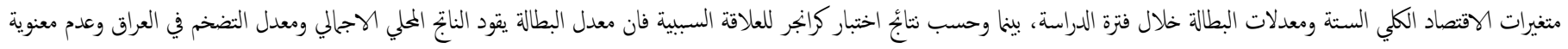

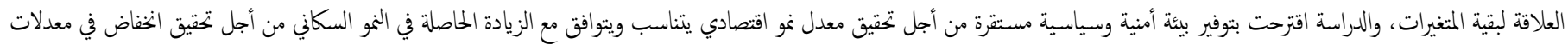

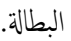

الكلمات الدالة: البطالة، الانفاق، أسعار النفط، أجالي الناجتج المحلي ، العراق .

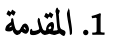

الاجالي في العراق، وقد يرجع ذلك لعدم وجود استثمارات اجنية داخلة الم العراق

$$
\text { 2. الا بعد سنة } 2003 \text { (مرعاني وأسعد، 2014). }
$$

1.2

يتضح من نتابُ الدراسات السابقة وجود تركيز واضح على العلاقة بين متغيرات الاقتصاد الكلي ومعدلات البطالة والنمو الاقتصادي والاسواق المالية في الدول المتقدمة (Eryigit, 2009; Berk \& Aydogan, 2012)، بينا لم تبحث هذه العلاقة بشكل واسع لحد الان في الدول النامية (Arouri \& Rault, 2010)، Creti, Ftiti \& ) وأيضاً كنت نتأج هذه العلاقات متضاربة وغير واضحة . (Guesmi, 2013; Basher, Haug \& Sadorsky, 2010; إن الاضطرابات السياسية الأخيرة في العالم قد ادى المى زيادة معدلات البطالة ولحل هذه المشكلة فقد أزداد أهمية موضوع الاستثمار الأجنبي المباشر من المنظور الاقتصادي والاجتاعي، ويعتبر خلق فرص العمل للشباب والنمو السكاني في المنطقة في الوقت الحاضر مقياساً وشرطا أساسيا للاستقرار الاجتاعي. إن
إن البطالة في الوقت الراهن أصبحت تمس تماسك الجمتمعات واستقرارها وخاصة في الدول النامية ومنها العراق نتيجة أثارها السلبية وخطورتها نتيجة تزايد أعداد العاطلين وجز الدولة في احتواءها من خلال توفير فرص العمل لمم وخاصة في ظل معدلات النمو السكاني العالي وانهيار المؤسسات والثركات الانتاجية بسبب الحروب المتعاقبة وعدم كفاءة القطاع العام والتحول المى اقتصاد السوق عن طريق الخصخصة ، كلها عوامل أدت الى تفامة المثكلة ،ولتقليل معدلات البطالة فان الدول المتقدمة والنامية لجأت الى انباع سياسات مالية ونقدية عديدة لجذب التدفقات الاجنية من رأس المال أو الخبرات العلمية او الادارية لتحقيق زيادات في النمو الاقتصادي وخلق فرص عمل جديدة وفتح أبواب الاسواق المحلية للتبادل لامتصاص الطاقة الشبابية العاطلة عن العمل. حيث أن العلاقة بين الاستثمار الأجنبي المباشر والنمو يختلف من فترة إلى أخرى وخاصة في الاقتصاديات المتقلبة كبيئة العراق مع وجود مستوى عال من عدم استقرار متغيرات الاقتصاد الكلي، وباعطاء احتالية دور للاستثمار الأجنبي المباشر في عملية النمو الاقتصادي (أسعد، 2014، 193). ببنا لوحط قلة وجود دراسات تربط العلاقة بين تدفقات الاستثمار الاجنبي المباشر ونمو الناتج المحلي 


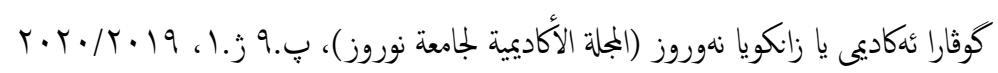

الستة الرئيسية ومعلات البطالة، حيث أن فكرة اختبار الفرضية هي لتحديد أهمية النوذج المستخدم، وفرضيات الدراسة الحالية هي كالاتي: الفرضية الاولى: لاختبار فيا اذا كان هناك علاقة تكمل مشتركة طويلة الاجل بين متغيرات الاقتصاد الكلي ومعدلات البطالة خلال فترة الدراسة. الفرضية الثانية: تفتزض الدراسة وجود علاقة سبية ذات اتجاه واحد من كل من متغيرات الاقتصاد الكلي إلى معدلات البطالة خلال فترة الدراسة، ولا توجد علاقة سبية ذات الجاه واحد من معدلات البطالة إلى كل من المتغيرات المستقلة خلال فتزة الدراسة. الفرضية الثالثة: لفترة تواجد داعش تأثير سلبي على معدلات البطالة في العراق خلال فتزة الدراسة.

\section{2 نطاق الدراسة ومصادر البيانات}

استخدم الدراسة مشاهدات سلسلة سنوية لمتغيرات الاقتصاد الكلي لكل من عرض النقد، الانفاق، الاستثار الاجنبي المباشر، سعر النفط، الناتج المحلي الاجالي، معدل التضخم كتنغرات مستقلة إلى معدلات البطالة كتغير معتمد خلال فترة الدراسة الممتدة (1994-2018). تم استخدام بيانات السلاسل الزمنية من مصادر ثانوية والتي تم الحصول عليها من مصادر عديدة وختلفة ومنها قواعد بيانات خختلفة، مثل المنشورات والتقارير السنوية للبنك المركزي العراقي وقاعدة البيانات للبنك الدولي ومؤتمر الام المتحدة للنجارة والتنمية وصندوق النقد الدولي وصندق النقد العربي وإدارة معلومات الطاقة الأمريكية .

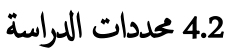

ان لهذه الدراسة محددات على الرغز من أن الهدف هو لتحديد العلاقة بين متغيرات

$$
\text { الاقتصاد الكلي ومعدلات البطالة، ومنها: }
$$

تركيز الدراسة على متغيرات الاقتصاد الكلي ومعدلات البطالة في العراق،

وعدم شمولها لدول اخرى على الرغز من وجود دول اخرى تشبه العراق في اعتمادها على النفط في تمويل نققانها كالسعودية وايران، واعتماد هذه الدراسة على مشاهدات سلسلة زمنية سنوية لمدة أربعة وعشرون سنة فقط للفتزة

(2018-1994)
الاقتصاد العراقي لم يعاني من مشكلة البطالة في سبعينات وثمانينات القرن الماضي نتيجة عدم تجاوز النسبة أربعة بالمئة من إجالي قوة العمل والتي كانت مقبولة اقتصادياً بينما العراق حاليا تعاني من البطالة حسب الجهاز المركزي للإحصاء العراقي حيث أن نسبة البطالة بين الثباب في العراق تجاوز 22\%، بينها أعلن صندوق النقد الدولي في أيار 2018 بأن معدل البطالة للشباب في العراق تجاوز 40\%، وبناء على ذلك فان هذه الدراسة تحاول الاجابة على الاسئلة أدناه: هل هناك علاقة تكامل مشتركة طوية الاجل بين متغيرات الاقتصاد الكلي كعرض النقد، الانفاق، الاستثار الاجنبي المباشر، سعر النفط، الناتج المحلي الاجالي، معدل التضخم ومعدلات البطالة في العراق خلال فترة الدراسة. هل يوجد علاقة سبية ذات اتجاه واحد من كل من متغيرات الاقتصاد الكلي المختارة إلى معدلات البطالة في العراق خلال فترة الدراسة؟ وهل يوجد علاقة سبية ذات اتجاه واحد من معدلات البطالة إلى هذه المتغيرات المشار الهيا في

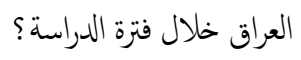
هل يوجد تأثير سلبي لفترة تواجد داعش على معدلات البطالة في العراق خلال فتزة الدراسة. 2.2 أهمية الدراسة تأتي أهمية هذه الدراسة كإضافة للاطار المعرفي حول استكشاف العلاقة بين متغيرات الاقتصاد الكلي ومعدل البطالة في دول نامية والتي لديها اقتصاد محدود بحيث لايتجاوز عمرها العقد من الزمن كالعراق، وبالتالي فتح المجال لباحثين آخرين لتطوير هذه الدراسة بإضافة متغيرات أخرى أو إجراء دراسات جديدة.

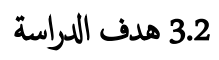

إن الهدف العام لهذه الدراسة يتمثل في معرفة العلاقة المحتمة على المدى الطويل والمدى القصير بين المؤشرات المالية، المؤشرات الخارجية ومؤشرات الإنتاج الحقيقي ومع مؤشر البطالة للفتزة الممتدة (1994-2018)، وكذلك تهدف الى معرفة فيا اذا كان هناك تأثير سلبي لفترة تواجد داعش على معدلات البطالة في العراق خلال فترة الدراسة.

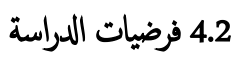
إن اختبار الفرضيات سوف توضح الهيكل والعلاقة بين متغرات الاقتصاد الكلي 


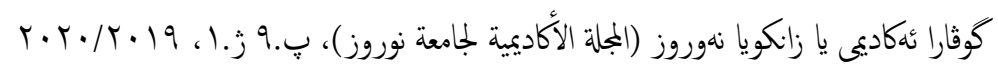

وراغب فيه وييحث عنه ويقبله عند الأجرالسائد ولكن دون جدوى (بجلخ ،

. ( 65 ، 2016

\section{3 انواع البطالة تمثل في الاتي}

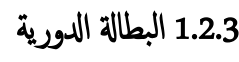

يتكرر حدوث هذا النوع من البطالة دورياً مع حدوث التقلبات والأزمات الاقتصادية التي تحدث بشكل دوري وشبه منتظم في الدول الصناعية ، وتحدث هذه البطالة نتيجة لقلة الطلب على السلع والخدمات وانخفاض الأسعار وانخفاض الأجور مع انخفاض استثمرات رؤوس الأموال في المشاريع الإنتاجية ، وهذا الركود

يسبب زيادة معدلات البطالة ( عمر ، العاني ، 1991، 237 ).

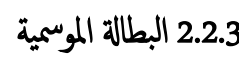

تحدث التغيرات في الطلب على السلع والخدمات خلال مواسم السنة ، فيزداد الطلب على سلع معينة خلال موسم معين وينخفض الطلب عليها في مواسم اخرى ، فنثلا عندما ينخفض الطلب على عال البناء في فصل الشتاء لأن الجو بارد ومطر والنهار قصير والليل طويل فينخفض طلب أصحاب البناء على البناء ، وبالتالي يقل samuelson , ) الطلب على عال البناء فيصبح هؤلاء العمال عاطلين عن العمل . (1997, 243

\subsection{3 البطالة الصناعية}

يظهر هذا النوع من البطالة عند اكتشاف آليات ومكائن حديثة تستطيع أن تحل محل الإنسان في العملية الإنتاجية، الأمر الذي يؤدي الى تسريخ أعداد كبيرة من العمال سيكونون هؤلاء ضمن جيش العاطلين عن العمل .

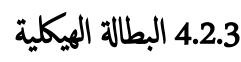

بين كل فترة واخرى يتغير هيكل وبناء الاقتصاد ، فتوجد صناعات كيرة تنتعش ويكون الطلب عليها عالياً في أوقات معينة ولكن سرعان ما يتغير هيكل هذه الصناعات وتظهر صناعات جديدة اوتختفي الصناعات القديمة ، والأمثلة على ذلك صناعة بناء السفن والقاطرات واستخراج الفحم الحجري والحديد من باطن الأرض وصناعة الحديد والصلب حيث اختفت هذه الصناعات في بداية القرن العشرين في بريطانيا بعد أن كانت منتعشة في القرن التاسع عشر لاسيا في شمال بريطانيا ( الحسن ، الحسب ، 1982 ، 195 ) ).
إن نموذج الدراسة تضمن بعض متغيرات الاقتصاد الكلي وبالامكان أضافة متغيرات أخرى كأسعار الذهب، او الحكم الرشيد أو مؤشرات الفساد في الدراسات المستقبلية المشابة لتحسين وتطوير التغيرات في النتائج المنعلقة بتأثير تغيرات متغيرات الاقتصاد الكلي على معدلات البطالة، أو من الممكن اضافة متغيرات غير اقتصادية كالأخطار السياسية والإرهاب والفساد والانتخابات وتوتر العلاقة بين المركز واقليم كردستان وغيرها، وكلها عوامل

$$
\text { تؤثر على ثقة المستثمر والشركات والقرارات الحكومية. }
$$

3. الاطار النظري للبطالة والدراسات السابقة

1.3 ماهية البطالة

يصعب ايجاد تعريف موحد للبطالة لكونها من المفاهيم الاقتصادية والسياسية والاجتاعية الواسعة ، لذلك توجد هنالك العديد من التعاريف حسب وبجة نظر وتخصص كل مفكر ، ومن اهم ما ذكر حول دلالات البطالة :-

1.1.3 التعريف الاصطلاحي

اصطلاحا كلمة البطالة لها معاني وهي ( بلعباس ، 2012 ، 11 ) ، اولا:عدم تناسب فرص العمل مع قوة البشر او قلة هذه الفرص مع المعروضة مع كثرة الطلب عليها .ثانيا :عدم اسناد العمل ايا كان نوعه الى الشخص ، واخيراعدم قيام الشخص بعمل ما بناءا على رغبته في عدم العمل .

2.1.3 ت تعريف المكتب الدولي للعمل

اشار المكتب الدولي للعمل تتكون فئة العاطلين عن العمل من كل الاشخاص الذين تتزاوح اعاره بين ( 16 و 59 سنة ، ووجدو نقسهم في يوم معين او اسبوع معين في احد الفئات التالية ( جباري ، 2015 ، 11 ) :-بدون عمل : اي الذين لا يعملون مقابل اجر -متاح للعمل : اي الذين باستطاعتهم القيام فورا بالعمل . -ييحث عن العمل : اي الذين اتخذوا خطوات محددة خلال فترة معينة للبحث عن

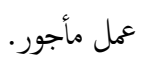

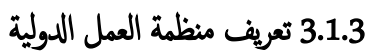

حسب منظمة العمل الدولية فإن العاطل عن العمل هو كل إنسان قادر على العمل 
تؤثر البطالة على الحالة الاقتصادية للعاطلين عن العمل ، حيث ينخفض دخلهم الى الصفر فيلجأ العاطلين الي السحب من ادخاراتهم السابقة وبالتالي انخفاض نسبة ادخاراتهم ، هذا من ناحية ، من ناحية اخرى انخفاض الدخل يؤدي الى انخفاض مستوى الانقاق والذي يؤثر سلبيا على صحة الافراد والذي يؤدي الى انخفاض انتاجيته في حالة عودتهم الى العمل . وان انخفاض الادخارات والانفاق وانخفاض انتاجية العامل يؤثر سلبا على الاقتصاد كلل ، فيحدث ركود في الانتاج والبيع والشراء الذي يؤدي المى انخفاض الاستثمرات التي تكون بمثابة محرك اساسي للنشاط الاقتصادي وبالتالي انخفاض معدل نمو

$$
\text { الناتج المحلي الاجالي ( حسين وسعيد ، } 2004 \text { ، 332-33 ) . }
$$

انتشار الفقر : يعد الفقر من أبرز المشاكل الكبيرة و المزمنة و التي تواجه كثيرا الدول النامية ، فزيادة معدلات البطالة يؤدي الى انخفاض دخل الفرد وانتشار ظاهرة الفقر بشكل كير.إذن فالفقر ينتج من المستوى المنخفض للنمية الاقتصادية وازدياد البطالة .

\subsection{3 الهار الاجتاعية والنفسية للبطالة}

تؤدي البطالة الى تدهور الحالة النفسية والاجتاعية للعاطلين عن العمل ، حيث تجعهم يعيشون في حالة من الاحباط وعدم الثقة بالنفس ، مما يؤدي الم ظهور العديد من المشاكل الاجتتاعية اهمها :-

ازدياد حالات الانتحار التي ترتبط بعلاقة طردية مع البطالة ، حيث ان زيادة معدلات البطالة يؤدي الى ازدياد حالات الانتحار ، هذا من نا حية ، من ناحية اخرى ، تزداد معدلات الجريمة بازدياد معدلات البطالة ، حيث ان انخفاض دخل العاطلين عن العمل يضطره الى الهخراط في صفوف الجمرمين Sinclair , 1987 , 34-) اجل الحصول على دخل لاعالثه واعالة عائلته $(35)$ في دراسة اجراها هارفي برينبر عن اثر البطالة على التكلفة الاجتاعية والنفسية المجتمع استنتج بأنه بزيادة معدل البطالة بنسبة 1\% عن المعدل الفعلي قد ادى المى زيادة معدل الانتحار بنسبة 4\% وزيادة معدل الجرائم بنسبة 6\% ، وزيادة الدخول الى المصحات النفسية بجوالي 4\% ( حسين

$$
\text { وسعيد ، } 2004 \text { ، } 233 \text { ) }
$$

5.2.3 البطالة الحتكاكية

تحدث البطالة الحتككية بسبب التنقلات المستمرة للعاملين بين المناطق والمهن الخخلفة و تحدث عادة بسبب نقص المعلومات لدى الباحثين عن العمل وعن فرص برص برن العمل المتاحة فيه ( رمزي ، 1997 ، 20) .

6.2.3 البطالة المقنعة

وتسمى ايضا بالبطالة المستترة وهو نوع البطالة الأشهر في الفكر الاجتاعي الاقتصادي والاكتز انتشارا خاصة في الدول الاشتراكة و في الدول العربية وخاصة في قطاع الخدمات والقطاع الزراعي. والبطالة المقنعة أو المستتزة هي العمل ولو لكل الوقت المعتاد ولكن بمستوى أنتاجي منخفض، أو دون استغلال كامل للمهارات والمؤهلات والقدرات، وتصل انتاجية العامل احيانا الى الصفر، ومع ضعف القدرة على الوفاء بالحاجات، (منظمة العمل الدولية ، 1993 ، 264 ) .

\subsection{3 البطالة الإجبارية أو القسرية}

وتحدث هذه البطالة عندما يضطر أو يجبر العامل على ترك عملة بسبب أو لأخر ، بسب اعلان مشروع ما عن إفلاسه مثلاً ،أو عندما يغلق أحد المصانع أبوابه ويستغني عن العاملين فيه أو بعضهم بغير إرادتهم ( رمزي ، مصدر سابق ، 34 ) .

\subsection{1هار المترتبة على البطالة}

تعتبر البطالة من المشاكل الرئيسة التي تواجه المجتمعات وتترك اثارا كبيرة على المجتع في جميع النواحي ، سواء على الناحية الاقتصادية او الاجتماعة ، سنطرق في هذه الفقرة الى اهم الاثار التي تترتب على ظاهرة البطالة .

1.3.3

تترك البطالة اثار سلبية مباشرة على الحالة الاقتصادية للمجتمع او على العاطلين عن

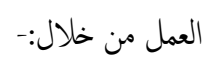

ان زيادة عدد العاطلين على العمل يعني بأن هناك هدر في استخدام الموارد البشرية ، مما يؤدي الى انخفاض الانتاج الفعلي عن الانتاج الممكن . 


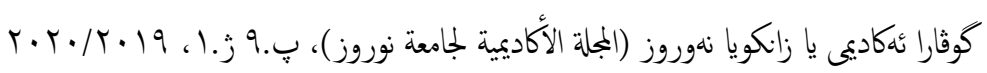

عمل الجامعات بدون خطة مدروسة نتيجة خلل في المؤسسات التعلمية فتقوم هذه الجامعات بتخريج الالاف من الطلاب بتخصصات لا يمتاج الهيا سوق العمل فيحدث هناك جفوة بين عرض العمل والطلب عليه ، فتزداد نسبة البطالة. .

الانقجار السكاني النابم عن التخلف الاقتصادي في الدول النامية ، وبالتالي الزيادة في القوى العاملة الذي يؤدي المى حدوث عدم التوازن بين عرض

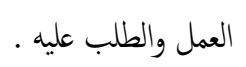

قد تحدث البطالة في تخصصات معينة مع العلم ان بعض جحات الدولة بحاجة الى هذه التخصصات ، وتحدث هذه الحلالة عندما يكون هناك عدم توزيع القوى البشرية حسب تخصصانهم العلمية ، او ان يعيش الاقتصاد حالة من الكساد العام الذي يشمل جميع القطاعات ( ويرنت ، 166 ) . قلة كفاءة المسؤولين في تسيير شؤون الدولة ، وظهور المنتفعين من مناصبه والمحسوبية ، و وعدم تحديث اساليب العمل او التوسع في الانتاج ، او فتح مشروعات جديدة ، او تشغيل العاطلين في اعمال مؤقتة وباجور متدنية وبدون عقد او تامينات ، كل هذا ادى اللى تهميش العديد من الكفاءات وعدم استغلال الطاقات البشرية وبالتالي تفاقٌ مشكلة البطالة (ناصر ، 180 ) . موسمية بعض الاعمال وبقاء العال في حالة البطالة خلال مواسم معينة من السنة، بسبب العادات الاجتاعية والظروف المناخية ، او تهاون العامل في البحث عن العمل وعدم البحث الجدي والفعال عن العمل المناسب ، وعدم وصول بعض الدول المى التشغيل الكامل لقوة العمل حتى في الدول قليلة

$$
\text { السكان ( سعيد ، } 1989 \text { ، } 17 \text { ) }
$$

\section{3 الدراسات السابقة}

أ. دراسة ( ندوة هلال جودة و رجاء عبدالله عيسى ) عام 2010 بعنوان ( العلاقة بين النمو الاقتصادي والبطالة في العراق باستخدام قانون (okun)

$$
\text { واختبار Toda - Yamamoto }
$$

بينت الدراسة ان تقدير معامل اوكن اعطى معلمة غير معنوية اي ان القانون غير ملائم تطبيقه ي الاقتصاد العراقي بسبب ان البطالة في العراق لاتتغير
تؤدي البطالة الى ظهور انحرافات في اخلاق الافراد تخالف العادات والتقاليد والدين ، فعندما يعيش الفرد الام الفتر والحرمان هو وعائلنه نتيجة لفقدانه لدخله ، فان هذا سيدفعه الى الحقد والكراهية واللجوء الى السرقة وتعاطي الخخدرات وغيرها ( مأرب بريس ، ، 3 ) ، فيتولد نتيجة لذلك شعور بالاحباط والفشل لدى الافراد العاطلين ، ويسيطر عليهم حالة الملل ويرفع شعار التمرد ضد امن بلده ، فلا يوجد اثقل من النفس التي تجرع مرارة الفقر والحرمان والعوز المادي ، وخاصة عندما يكون الفرد مسؤولا عن اعالة عائلنه ، فنتدهور علاقته مع المجتمع ومع اصدقائه ويشعر بانه غير قادر على المساهمة في بناء المجتع ويخلق لديه انطباع بانه عالة على المجتع فيفضل حالة العزلة وعدم اختلاط بالمجتع ( فرج واخرون ، 2008 ، 5) . تاخر زواج الشباب ، وتخلي الاباء عن مسؤوليتهم تجاه تعليم ابنائهم واجبارهم على ترك مقاعد الدراسة بسبب انخفاض قدرتهم المالية التي تمكنهم من مساعدة ابنائهم على مواصلة الدراسة وزجحم في سوق العمل ، وبالتالي انتشار حالة عمل الاطفال ، وتفشي الفقر والجهل والاوبئة داخل المجتع ( بوشامة مصطفى ، ، 7 ) . (5) ان قلة فرص العمل وانخفاض مستويات المعيشة تدفع الافراد العاطلين عن العمل الى البحث عن هذه الفرص خارج الوطن ، فتزداد معدلات الهجرة بشكل كير نتيجة زيادة معدلات البطالة (سعيدي يجيى واخرون ، ، ) .

4.3

هناك العديد من الاسباب التي تقف خلف ظهور مشكلة البطالة وتزيد من حدتها ، وقد تختلف هذه الاسباب من مجتع الى اخر او من نظام اقتصادي الى اخر، ولكن بصورة عامة يككن تقسيم اسباب البطالة المى نوعين هـا : 1- الاسباب الداخلية: وتتمثل بالعوامل المحلية التي ادت الى ظهور مشكلة البطالة والمتعلقة بالسياسة الداخلية للمجتع وتشمل ( صالح ، 2004 ، 90 ) :انتقال العحال من وظيفة الى اخرى ومن صناعة الى اخرى ، وهذا الانتقال قد يستغرق وقت معين وخلال فترة هذا الاقططاع عن العمل يعيش العال حالة البطالة، او قد يتطلع العامل الى نموذج معين من العمل وينظر الى ان يحصل على الوظيفة المناسبة . 


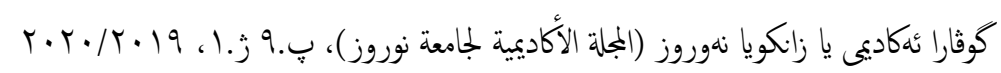

للاقتصاد العراقي نتيجة للحروب المذكورة والتزكيز فقط على الجانب الامني على حساب خطط التنمية الاقتصادية وغياب الاستثار الاتناجي ، بالاضافة الى سياسات الخصخصة والانقاح على العالم الخارجي بشكل مفاجئ .

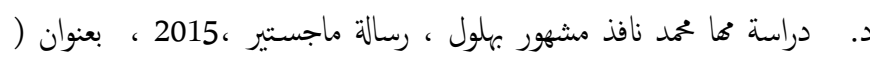
المحددات الاقتصادية للبطالة في الاراضي الفلسطينة دراسة قياسية ( 1995 - 2012 ) قامت هذه الدراسة بقياس اثر الالمددات الاقتصادية غلى معدلات البطالة في فلسطين باستخدام المنهج الوصفي التخليلي لوصف خصائص الظاهرة واستخدام المنهج القياسي لتحليل وتفسير اهم المثغيرات الاقتصادية المؤثرة على البطالة ، وتوصلت الدراسة الى وجود علاقة عكسية بين ( معدل النمو الاقتصادي ، ومعدل التبادل التجاري ، ونسبة الانفاق الاستثاري ) كتغيرات مستقلة والبطالة كتنغير تابع ، ووجود علاقة طردية بين التضخم والبطالة. هـ. دراسة سليم مخلج، عام 2016 بعنوان ( محددات البطالة في الجزائر ) تناولت هذه الدراسة الإطار النظري والنظريات المفسرة لمشكلة البطالة في الجزائر ومحدداتها من خلال تحليل وقياس أثر المتغيرات المفسرة على متغير البطالة ، إضافة إلى تقدير وبناء نموذج لتحديد المتغيرات المؤثرة والمحددة للبطالة خلال المدة 2014 / 1985. وقد اعتمدت الدراسة على الأسلوب الإحصائي الكمي القياسي من أجل إجراء الدراسة القياسية وتحديد النموذج الأمثل لتفسير المشكلة وتوصلت الدراسة الى وجود علاقات سببية في اتجاه واحد بين النفقات العامة والناجُ الداخلي الخام الحقيقي، ومعدل البطالة وحجم السكان، والناتج الداخلي الخام الحقيقي ويجم السكان( وعلاقة سبية في التجاهين بين النقات العامة وحجم السكان.و هنالك علاقة ذات دلالة إحصائية عكسية إيحابية بين معدل البطالة والنفقات العامة على المدى المثوسط والطويل، وهناك علاقة عكسية إيجابية ذات دلالة إحصائية بين الناتج الداخلي الخام الحقيقي ومعدل البطالة على المدى الطويل، وعلاقة طردية على المدى القصير.والعلاقة تكون طردية سلبية ذات دلالة إحصائية بين حجم السكان ومعدل البطالة في المدى القصير والطويل. والعلاقة بين معدل التضخم ومعدل البطالة نكون عكسية.
حسب الدورة الاقتصادية من جهة وان سوق العمل غير مرن من بجة اخرى، كما توصلت الى ان العلاقة بين النمو الاقتصادي ومعدل البطالة علاقة باتجاه واحد بسبب ضعف الارتباط بين الناج ومعدل البطالة في الاقتصاد العراقي لاعتاده على قطاع النفط في تكوين الناج ما حد من قدرة الاقتصاد في امتصاص الزيادة الحاصلة في عرض العمل، وان العلاقة السبية وفق اختبار Toda-Yamamoto من البطالة الى معدل نمو الناتج يعني ان البطالة تؤثر بشكل سلبي في النمو الاقتصادي فوجود حجم متزايد من البطالة من المؤكد ان يؤدي المى هدر واستنزاف كل الموارد . ب. دراسة ( جلال شيخ العيد و عيسى بهدي ) عام 2012 بعنوان ( قياس اثز النمو الاقتصادي على معدلات البطالة في الاراضي الفلسطينية للفترة 1996 ( 2011 حاولت هذه الدراسة تقديم معالجة قياسية للعلاقة بين النمو الاقتصادي ومعدلات البطالة في الأراضي الفلسطينة، للفترة الممتدة بين سنتَّ 1996 و 2011 ، واعتمدت على التحليل الوصفي وتقدير نموذج يربط متغير البطالة مع الناجت المحلي الاجلالي في كل الأراضي الفلسطينية عامة، وفي الضفة الغربية، وقطاع غزة كل على حده. وهدفت إلى معرفة مدى تحقق قانون ئمun الواقع الاقتصادي الفلسطيني مستعيناً بعض المؤشرات الاحصائية، وقد توصلت الدراسة الى ان سلوك دالة البطالة في الضفة الغربية يختلف عن سلوك دالة البطالة في قطاع غزة، ووجود علاقة عكسية بين معدل النغير في معدل النمو في الناتج المحلي الاجلالي، والتغير في معدل البطالة في الاقتصاد

$$
\text { الفلسطيني ولكن بمعدلات مختلفة عن الاقتصاد الامريكي. }
$$

دراسة د. عيادة سعيد حسين عام 2012 بعنوان ( البطالة في الاقتصاد ? العراقي ، اسبابها وسبل معالجها ) بينت هذه الدراسة بان الاقتصاد العراقي قد عانى من معدلات مرتفعة للبطالة خلال الفترة 1982-2006 بسبب اثار الحرب العراقية - الايرانية ، وحربي الخنيج الاولى والثانية ، ومن ثم الحصار الاقتصادي الى عام 2003 ، وتوصلت الدراسة الى ان النسبة الاكبر من البطالة كانت بين الشباب حيث بلغت عام 200650.5 \% ، واغلهم خريجي الكليات وخريجي الاعدادية ، وبينت الدراسة ان اسباب ارتفاع نسبة البطالة يعود الى تدمير البنى التحتية 


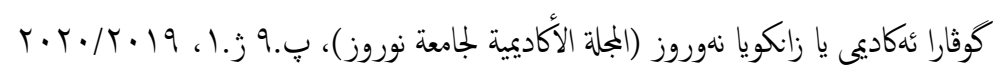

ومعدل التضخم) ومعدل البطالة في الدول تحت الدراسة. وياتي الجانب التطبيقي بعد

$$
\text { تناول الإطار النظري والدراسات السابة وتتضمن الاتي: }
$$

\section{4 توصيف انموذج الدراسة}

تم اختيار ستة متغبرات للاقتصاد الكلي في هذه الدراسة وادخلت في ثلاث مجموعات: المجموعة الأولى تتضمن مؤشرات مالية تمثل عرض النقد والانفاق المالي. المجموعة الثانية تتضمن مؤشرات خارجية تمثل في الاستثار الاجنبي المباش وسعر النفط، بينا تعرض المجموعة الثالثة مؤشرات الإنتاج الحقيقية والتي يتم قياسها بواسطة مؤشر النمو الاقتصادي ومعدل التضخم. تم إجراء هذه الدراسة في العراق لها ميزة الموق الاستراتيجي. أيضا، سوف تتضمن هذه الدراسة مؤشرات القدرة التنافسية الخارجية التي تلعب دورا هاما في الاقتصاد، حيث سيكون عرض النقود والانفاق تحت المؤشرات المالية ( Wongbangpo \& Sharma، Vuyyuri 2002 ؛ 2005)، والاستثار الاجنبي المباشر وسعر النفط العالمي سيكون تحت المؤشرات الخارجية ( Gay ، 2008). أخيرًا تم اعتبار متغيرات النمو الاقتصادي ومعدل التضخم كؤشر للإنتاج الحقيقي ( Wongbangpo \& Sharma، 2002)، وبالتالي تقوم الدراسة بتحليل العلاقة بين متغيرات الاقتصاد الكلي الستة مع معدل البطالة في العراق، لذلك فان نموذج الدراسة تم تحديده بان معدل البطالة متغير معتمد ومتغيرات الاقتصاد الكلي كتغيرات مستقلة في النموذج ويختصر بالاتي:

\section{Estimation Command: LS UNE M1 EX FDI OP GDP INF}

Estimation Equation: $\mathrm{UNE}=\mathrm{C}(1)^{*} \mathrm{M} 1+\mathrm{C}(2)^{*} \mathrm{EX}+\mathrm{C}(3)^{*} \mathrm{FDI}$ $+\mathrm{C}(4)^{*} \mathrm{OP}+\mathrm{C}(5)^{*} \mathrm{GDP}+\mathrm{C}(6)^{*} \mathrm{INF}+\mathrm{C}(7)+\mathrm{e}$

Estimation Equation: $\mathrm{UNE}=\mathrm{C}(1)^{*} \mathrm{M} 1+\mathrm{C}(2)^{*} \mathrm{EX}+\mathrm{C}(3)^{*} \mathrm{FDI}$ $+\mathrm{C}(4)^{*} \mathrm{OP}+\mathrm{C}(5)^{*} \mathrm{GDP}+\mathrm{C}(6)^{*} \mathrm{INF}+\mathrm{C}(7)^{*}$ DummyISIS + $\mathrm{C}(8)+\mathrm{e}$
و. دراسة د ـ الطاهر جليط عام 2016 بعنوان ( دراسة قياسية لمحدات البطالة

$$
\text { في الجزائر للفتزة } 1980 \text { - } 2014 \text { ) }
$$

حاول هذا البحث القيام بدراسة قياسية لأهم محددات البطالة في الجزائر خلال الفترة 1980 - 2014 وذلك باستعمال النادج الدينامكية (نمودج اشعة الارتباط الذاتي) والتي تكشف عن التفاعلات الدينامكية بين البطالة والمثغيرات المفسرة لها . وقد توصلت الدراسة الى ان محدادات البطالة في الجزائر تمثلت في معدل النموالاقتصادي والانفاق العام وسعر النفط وكان المحدد الرئيسي للبطالة هو الانفاق العام اله ان اثره كان ضعيفا نوعا ما في المدى القصيرحسب ما بينته نتاجُ تحليل الصدمات وتحليل التباين، ورجعت الدراسة سبب ذلك الى ان النفقات العامة في الجزائر كانت موججة في البني التحتية والتي عادة ما يكن عائدها على النمو الاقتصادي في المدى البعيد، وادى هذا إلى تأخير بيان اثر هذا الإنفاق في معدل البطالة. كما بينت نتاجُ الدراسة ايضا بان السياسة المالية هي اكثر فعالية في التخفيفي من حدة البطالة من السياسة النقدية . يتضح من الاستعراض السابق لبعض الدراسات التي اختبرت العلاقة بين متغيرات الاقتصاد الكلي ومعدلات البطالة في الدول النامية والمتقدمة او الموردة والمصدرة للنفط، بان هناك عدم وضوح وفقدان دليل قطي لحد الان يجدد العلاقة والثأثير بين هذه المتغيرات وبدوره يعطي فرصة للباحثين لاجراء المزيد من الدراسات حول هذا الموضوع. هذا فضلا عن وجود الفجوة في المعرفة نتيجة ندرة وقلة الاهنمام في الدراسات السابقة حول هذه العلاقة في الدول النامية مثل العراق ولكون العراق عضو مؤسس في منظمة الدول المصدرة للنفط (أوبك) والتي تمتلك (70\%) من الاحتياطي العالمي للنّطط، أي أعتبارها أحد الدول الرئيسة لتصدير النفط في العالم باحتياطي يقدر بـ (144.2) مليار برميل ( OPEC Annual Statistical معدل البطالة = UNE .(Bulletin, 2014

\section{4. المبحث الثاني: الجانب الثطبيقي للدراسة}

كان الهدف من هذه الدراسة هو اختبار العلاقة المختمة على المدى الطويل والقصير بين المؤشرات المالية (عرض النقود والانفاق)، المؤشرات الخارجية (الاستثار الاجنبي المباشر وسعر النفط) ومؤشرات الإنتاج الحتيقية (الناتج المحلي الاجلالي 


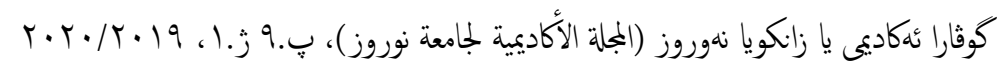

$B 7($ DumISIS $)+\varepsilon \mathrm{t}$

تم الاعتاد على المصادرفي الجدول (1) لتحديد متغيرات الدراسة حيث يمثل المتغير يمثل معدل البطالة الذي يتم تعريفه هنا على أنه عدد الأفراد العاطلين لكل 100 من أفراد القوى العاملة، م0 هو ثابت النموذج. المتغيرات المستقلة M1 و EX و

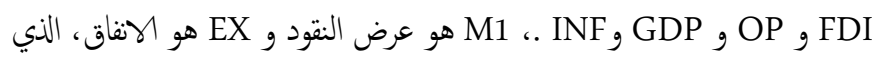
يمثل المؤشرات المالية. FDI هو الاستثمار الاجنبي المباشر الصرف و OP هو أسعار النفط العالمية التي تثثل المؤشرات الخارجية. GDP هو مؤشر الناتج المحلي الاججالي وINF هو معدل التضخم، والنان يمثلان مؤشرات الإنتاج الحقيقية والمتغير الوهي هو فترة تواجد داعش (ISIS). المعلمات في النموذج هي، 1 و 2 , و 3 م

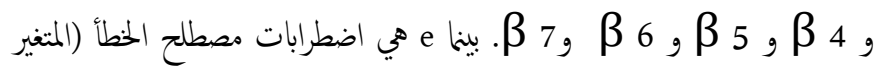

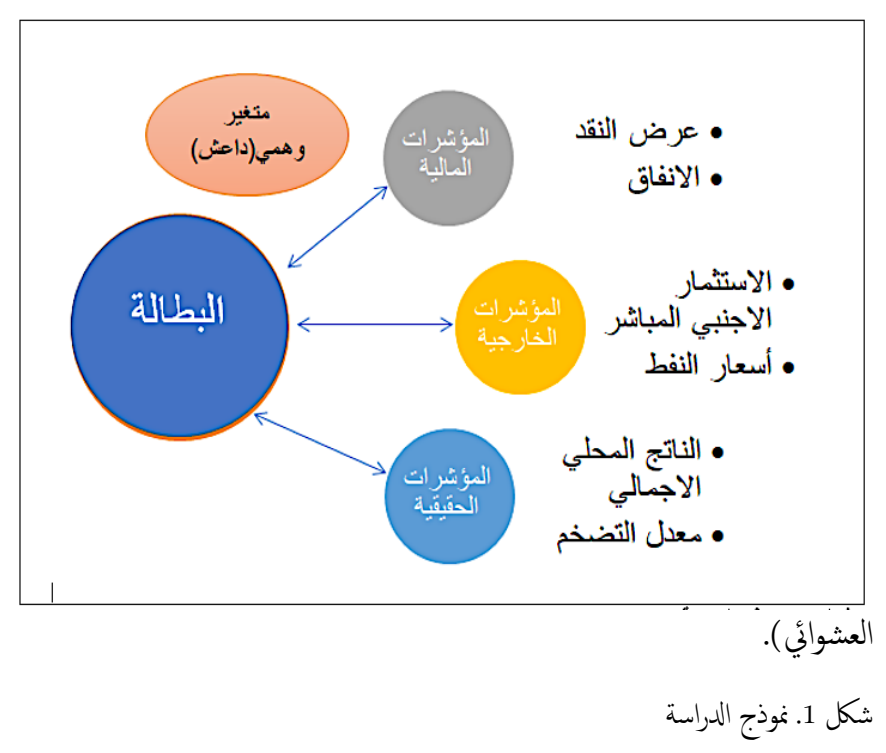

2.4 التعاريف الاجرائية (Operational Definitions)

في سياق هذه الدراسة، تم تحديد التعاريف الاجرائية على النحو المنصوص عليه في الدراسات السابقة أو النعاريف لبعض المؤسسات الاقتصادية الدولية أو المؤسسات المحلية لعينة الدراسة. آ. عرض النقد (Money Supply): عبارة عن مقياس ضيق للنقود المعروضة، ويشار له بالرمز (M1) ويُعبر عنه وفقاً للمعادلة الآتية: $\mathrm{M} 1=\mathrm{C}+\mathrm{DD}+\mathrm{OD}$

$$
\text { معامل الناتج المحلي الاجمالي C(5) }
$$

C(6)

$$
\text { C(7) }
$$

C(8)+C(7)

$$
\text { مساوية الصفر ). }
$$

$$
\text { e = المتغير العشوائي (النغير في الاسعار مع متوسط صفر ) e }
$$

وبالتالي، فان الدراسة تستخدم كلنا النظريتين، نظرية تسعير التحكيم والنظرية الاقتصادية، لشرح كف تؤثر متغيرات الاقتصاد الكلي المختارة على معدل البطالة. يوضح الشكل (1) العلاقة بين متغيرات الاقتصاد الكلي وتأثيرها على البطالة في العراق، حيث ان الشكل يقدم نظرة عامة على العلاقة بين المتغيرات التي سيتم

\begin{tabular}{|c|c|}
\hline 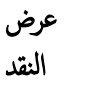 & $\begin{array}{l}\text { (Altay, 2003; Beenstock \& Chan, 1988; Clare \& Thomas, } \\
\text { 1994; Ozcam, 1997) }\end{array}$ \\
\hline الاتفاق & $\begin{array}{l}\text { (Altay, 2003; Roselee \& Fung, 2009; Kandir, (جليط، 2016) } \\
\text { 2008) }\end{array}$ \\
\hline الاستثمار & $\begin{array}{l}\text { (خلف، 2013: عبدمولاه،2011: البرواري والمعماري، 2007) } \\
\text { (Okafor, 2012; Glue, 2012; Nasir \& Hassan, } 2011 \text {; } \\
\text { Khan \& Nawaz, 2010; Amadi, 2002; Adebusuyi \& Salako, } \\
\text { 2001) }\end{array}$ \\
\hline
\end{tabular}

$$
\text { اختبارها في هذه الدراسة. }
$$

جدول 1

متغيرات الاقتصاد الكلي بالاعتاد على نمط نظرية التسعير بالمراجة

(Chan, et al., 1985; Chen \& Jordan, 1993; Clare \& Thomas, 1994; Roselee \& Fung, 2009)

(Cheng, 1995; Kandir, 2008; Kryzanowski \& Zhang, 1992;

Roselee \& Fung, 2009: Altay, 2003; Beenstock \& Chan,
المتصادي 1988; Burnmeister \& Wall, 1986; Chan, Chen \& Hsieh,

1985; Chen, et al., 1986; Ozcam, 1997)

(Altay, 2003; Chan, et al., 1985; Chen, et al., 1986; Burnmeister \& Wall, 1986; Chen \& Jordan, 1993)

$Y i=\beta_{0}+\beta_{1}(M 1)+\beta_{2}(E x)+\beta_{3}(F D I)+$

$\beta 4(O P)+\beta 5(G D P)+\beta 6(I N f)+\varepsilon \mathrm{t}(3.1)$

$Y i=\beta_{0}+\beta_{1}(M 1)+\beta_{2}(E x)+\beta_{3}(F D I)+$

$\beta 4(O P)+\beta 5(G D P)+\beta 6(I N f)+$ 


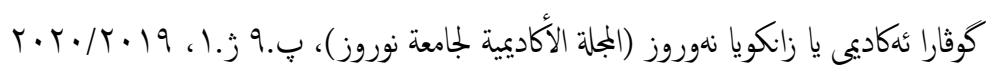

ه. الناتج المحلي الاجالي (Gross Domestic Product): يعرف النمو الاقتصادي بأنه الزيادة في كية السلع والخدمات التي ينتجها اقتصاد معين، وهذه السلع يتم إنتاجما باستخدام عناصر الإنتاج الرئيسية، وهي الأرض والعمل ورأس المال والتنظيم، كما يعرف كذلك بأنه تغيير إيجابي في مستوى إنتاج السلع والخدمات بدولة ما في فنرة معينة من الزمن، أي أنه زيادة الدخل لدولة معينة. ويتم قياس النمو الاقتصادي باستخدام النسبة المئوية لنمو الناتج المحلي الإجالي Gross domestic product) GDP وتقارن النسبة في سنة معينة بسابتها (منور، 2007). و. معدل التضخم (Inflation Rate): إن معدل التضخم يقيس الارتفاع العام في مستوى اسعار السلع والخدمات ومن ثم انخفاض القوة الشرائية. وان ارتفاع معدل التضخم يكون له تأثير سلبي وكبير على النمو الاقتصادي والاستثمار الأجنبي المباشر. وان معدل التضخم هو ميزة هامة من اساسيات الاقتصاد الجيد وكؤشر لعدم استقرار الاقتصاد الكلي ويعكس وجود توتر في الاقتصاد الداخلي وعدم المقدرة لدى الحكومة. ز. تواجد داعش (ISIS Emergence): وهو متغبر وهي يعبر عن الوضع السياسي اثناء فترة التنظيم في العراق والشام ،بمعنى أخر الفترة قبل وبعد داعش بحيث تم إضافة سلسلة زمنية اخرى تتمثل في إعطاء فترة تواجد داعش بالقيمة واحد، وهي الفنرة الزمنية التي كانت هناك تواجد لهذه المجموعة والتي تميزت بفترة عدم الاستقرار السياسي بسبب ممارساتهم الغير مسؤولة تجاه القيم الانسانية وتتمثل هذ الفترة ما بين (2013-2017)، أما باقي السنوات فقد أعطيت القيمة صفر على اعتبارها كانت بدون تواجد داعش. والدليل اذاكان المتغير الوهي (تواجد داعش) اصبح معنويا ومعامل التحديد كان موجبا، فذلك يعني بان تواجد داعش لديها تأثير على المتغير المعتمد وبالعكس. معدل البطالة (Unemployment Rate): تعرف البطالة وفق منظمة العمل الدولية ILO العاطل عن العمل هو ذلك الفرد الذي يكون فوق سن معينة بلا عمل و هو قادر على العمل و راغب فيه و ييحث عنه عند مستوى أجر سائد لكنه لا يجده (زكي، 1997: ص39). بينا معدل البطالة
العملة : هي العُملات المُتداولة بين الجمهور من الأفراد، (C) (Currency) وتتكوّن من المكونات الآتية: مذكرات التداول. تداولات العُملات النقديّة. احتياطات النقود عند كافة المصارف. الودائع تحت الطلب : هي الودائع الماليّة (DD) (Demand Deposits) الخاصة بالأفراد ضمن حسابات المصارف التجاريّة. (OD) (Other Deposits): هي الودائع الماليّة التي يتمُّ الاحتفاظ بها في المصرف الاحتياطي. ب. الانفاق (Expenditure): يعرف موسوعة المصطلحات الاقتصادية والاحصائية النفة العامة ما تنفقه الحكومة المركزية والسلطات المحلية والمشروعات العامة على السلع والخدمات بما فها الإنفاق الرأسلالي والإعانات والمنح والمدفوعات المحولة مثل فوائد الدين العام ومعاشات التقاعد (الأمين وعبدالغاني، 2002، ص (71). الاستثمار الاجنبي المباشر(Foreign Direct Investment): إن هذه الدراسة تتبنى نفس التعريف للاستثمار الاجنبي المباشر المقدم من قبل الهياكل الدولية كنظمة التعاون الاقتصادي والتنمية(OECD) ، مؤتمر الأم المتحدة للتجارة والتنمية (UNCTAD) وصندوق النقد الدولي (IMF) على انه استثارا ينطوي على علاقة طويلة الأمد ويعكس المصلحة الايمّة والمراقبة من قبل كيان مقيم في اقتصاد ما (المستثمر الأجنبي المباثر أو المؤسسة الأم) في مؤسسة مقيمة في اقتصاد آخر غير بلد المستثمر الأجنبي المباشر (الاستثمر الأجنبي المباشر أو المؤسسة التابعة لها أو فروع الثركات الأجنبية). الاستثار الأجنبي المباشر يعني أن المستثمر يمارس درجة كيرة من الثأثير على إدارة الكيان المقيم في اقتصاد الدولة الاخرى(UNCTAD, 2006) . د. سعر النفط (Oil Price): تشير أسعار النفط عادة إلى متوسط سعر استيراد النفط من منظمة النعاون الاقتصادي والتنمية (تأمين النكليف والشحن) كما حسبت وكالة الطاقة الدولية الأمريكية. تقيس أسعار النفط الخام السعر الفوري لختلف براميل النفط، في الغالب ، إما غرب تكساس الوسيط أو مزبج برنت. يتم أيضًا أحيانًا تحديد سعر سلة أوبك وسعر العقود الآجلة في بورصة (EIA, Annual Energy Outlook 2011). 


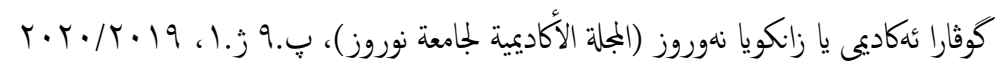

والاستثار الاجنبي المباشر بانحراف (2.48) وبمتوسط (1.49) بينا متوسط أسعار النفط هو (74.94500) وبانحراف معياري (2.48)، فيا كان متوسط الناتج المحلي الاججالي هو (1.45) وبانحراف معياري (6.72)، وبالاخير فان متوسط معدل التضخم كان (7.938915 ) وبانحراف معياري (18.14463)، ويجب أن تكون قيمة الالتواء (Skewness) وقيمة التفلطح (Kurtosis) قريبة من المتوسط أي قريبة من الصفر، ولنلك يكون من الصعب الهعتاد على القيمتين لتحديد إذا كان المشاهدات تتبع التوزيع الطبيعي أح لا، ولذلك يكن الاعتماد على اختبار جاك -بيرا في أن معدلات البطالة والمتغيرات المستقلة الستة غير ثابتة وانه لا تتبع التوزيع الطبيعي نتيجة كون مستوى المعنوية أقل من (5\%)، وبالثالي عدم استقرارية المشاهدات السنوية لمثغيرات الدراسة، حيث أن كل السلاسل الزمنية لمثغيرات الدراسة في العراق لم يتبع التوزيع الطبيعي وذلك لمعنوية اختبارية جاك بيرا. جدول 2

التوصيف الاحصائي للبيانات الاصلية لجمهورية العراق للفترة الممتدة (2003-2018)

\begin{tabular}{llllllll}
\hline \hline & UNE & M1 & EX & FDI & OP & GDP & INF \\
\hline Mean & 12.01357 & $5.88 \mathrm{E}+13$ & 2.798865 & $1.49 \mathrm{E}+09$ & 74.94500 & $1.45 \mathrm{E}+11$ & 7.938915 \\
Median & 9.765000 & $6.77 \mathrm{E}+13$ & 2.538557 & $1.50 \mathrm{E}+09$ & 68.80000 & $1.55 \mathrm{E}+11$ & 15.10031 \\
Maximum & 20.57000 & $9.30 \mathrm{E}+13$ & 5.346371 & $5.13 \mathrm{E}+09$ & 111.6300 & $2.35 \mathrm{E}+11$ & 32.30692 \\
Minimum & 7.550000 & $1.44 \mathrm{E}+13$ & 1.675589 & $-5.03 \mathrm{E}+09$ & 38.26000 & $3.66 \mathrm{E}+10$ & -26.10000 \\
Std. Dev. & 4.718301 & $3.11 \mathrm{E}+13$ & 0.973314 & $2.48 \mathrm{E}+09$ & 26.07646 & $6.72 \mathrm{E}+10$ & 18.14463 \\
Skewness & 0.506061 & -0.286782 & 1.276605 & -0.979032 & 0.213809 & -0.230360 & -0.516139 \\
Kurtosis & 1.680937 & 1.454759 & 4.324086 & 4.693917 & 1.581663 & 1.790276 & 2.179917 \\
& & & & & & & \\
Jarque-Bera & 1.612519 & 1.584768 & 4.825385 & 3.910300 & 1.280147 & 0.977489 & 1.013910 \\
Probability & 0.006525 & 0.005276 & 0.008957 & 0.001415 & 0.005272 & 0.006133 & 0.006023 \\
& & & & & & & \\
Sum & 168.1900 & $8.23 \mathrm{E}+14$ & 39.18411 & $2.08 \mathrm{E}+10$ & 1049.230 & $2.04 \mathrm{E}+12$ & 111.1448 \\
Sum Sq. & & & & & & & \\
Dev. & 289.4107 & $1.25 \mathrm{E}+28$ & 12.31541 & $7.98 \mathrm{E}+19$ & 8839.761 & $5.86 \mathrm{E}+22$ & 4279.959 \\
& & & & & & & \\
\end{tabular}

\begin{tabular}{llllllll} 
Observations & 14 & 14 & 14 & 14 & 14 & 14 & 14 \\
\hline \hline Eviews 8 المصدر: المداد الباحثة بالاعتاد على برنامج 14 & & & &
\end{tabular}

\section{4}

يعتبر اختبار العلاقة بين متغيرات الاقتصاد الكلي ومعدلات البطالة باستخدام السلاسل الزمنية الساكنة من الاساليب القياسية الحديثة من أجل تقديم نتائج واقعية ومتامشية مع العلاقات الاقتصادية المنطقية وذلك لتجاوز عقبة النتأجم الغير دقيقية (المزيفة) عند استخدام نماذج الانحدار التقليدية لوجود سلاسل زمنية غير ساكنة وبالتالي عدم اعطاءها تفسيرا اقتصاديا مناسباً للظاهرة قيد الدراسة على الرغ
فيعرف بأنه عدد الأفراد العاطلين لكل 100 من (Unemployment rate)

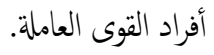

3.4 التوصيف الهحصائي

إن الفحص الأولي لطبيعة البيانات يكون خطوة أساسية قبل اتخاذ القرار بشأن الطريقة المناسبة للتحليل، ان الجانب التوصيفي يوضح مشاهدات السلسلة الزمنية التي أجريت الدراسة عليها والمتعلقة بمتغرات الاقتصاد الكلي الستة ومعدلات البطالة للفترة (2003-2017)، حيث تم القيام ببعض الاختبارات للتعرف على طبيعة البيانات قبل إجراء التحليل فثنلا تح عرض مشاهدات الدراسة السنوية في الشكل (2)، ويلاحظ عدم ثبات واستقرار اتجاه حركة معدلات البطالة في العراق لعدم وجود التجاه محدد لمتغيرات الدراسة، والشكل (2) يوضح التغرات السنوية في متغيرات الاقتصاد الكلي قيد الدراسة، والتي تظهر أيضاً العلاقة الطردية والعكسية والتناغ المى حد ما بين المتغيرات المستقلة ومعدلات البطالة خلال فتزة الدراسة أي انه كلما زاد أو انخفض احدى المتغيرات المستقلة أدى الى ارتفاع أو أنخفاض معدلات

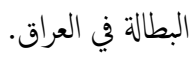

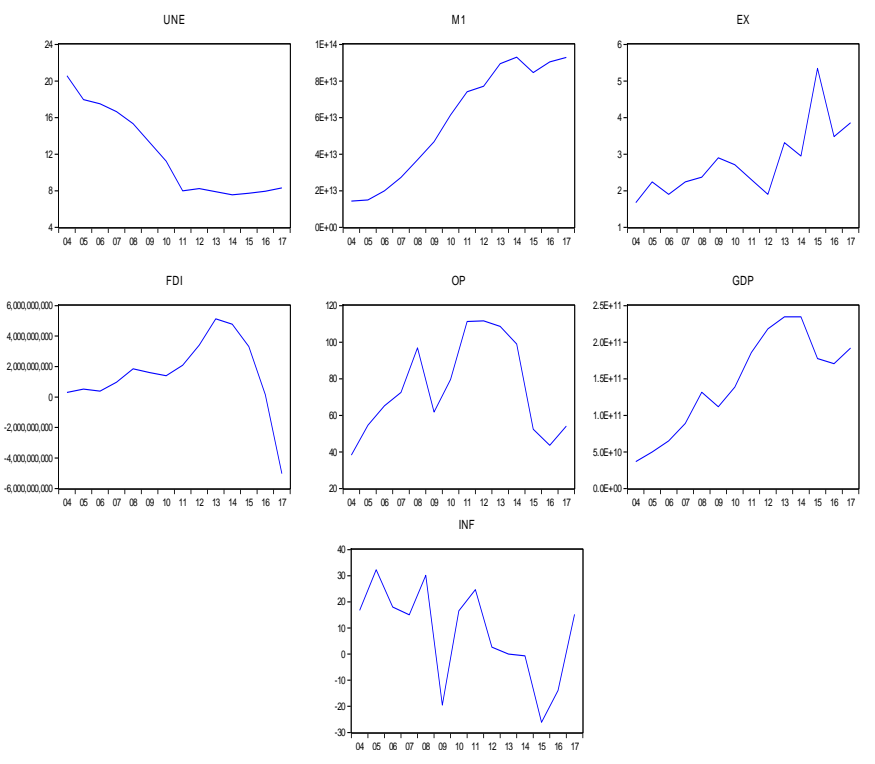

شكل 2. حركة متغيرات الدراسة لمههورية العراق للفترة الممتدة (2003-2018) إن التوصيف الاحصائي للسلسلة الزمنية لمتغرات الدارسة لجمهورية العراق يقدم دليل على عدم تبعية فرضية التوزيع الطبيعي، الجدول (2) يوضح بأن متوسط معدلات البطالة خلال فترة الدراسة هو (12.01357) وبانحاف معياري (4.718301)، بينها كان عرض النقد هو (5.88) وبانحراف معياري (3.11)، في حين كان للانفاق انحراف معياري (0.973314) ومتوسط (2.798865)، 


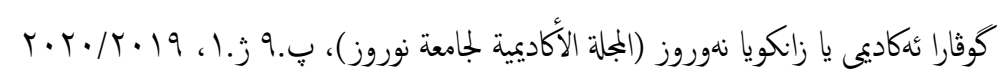

من دلالة الاختبارات الاحصائية المستخدمة، ولذلك استخدمت الدراسة اختبارات الملاحظات:

ADF -

- - علامة * تشير الى رفظ فرضية العدم من عدم الاستقرار عند مستوى معنوية

- - - طول الفترة المثالية لاختبار ديكي فولر المعدل يتم تحديدها بشكل اوتوماتيكي

$$
\text { بالاعتاد على طريقة معيار أكيكي للمعلومات (AIC). }
$$

- - القيم تكون على أساس ماكينون بجانب واحد (MacKinnon, 1996).

\begin{tabular}{|c|c|c|c|c|}
\hline \multirow{2}{*}{ المتغيرات } & \multicolumn{3}{|c|}{ اختبار ديكي فولر المعدل عند الفرق الاول } & \multirow{2}{*}{ الاستنتاج } \\
\hline & ثابت & ثابت واتجاه & بدون ثابت واتجاه & \\
\hline معدل البطالة & $-10.76285^{*}$ & $-10.74341^{*}$ & $-10.77106^{*}$ & $\mathrm{I}(1)$ \\
\hline عرض النقد & $-12.00025^{*}$ & $-11.97468^{*}$ & $-10.98494^{*}$ & $\mathrm{I}(1)$ \\
\hline الانفاق & $-9.442214^{*}$ & $-9.718703^{*}$ & $-9.368121^{*}$ & $\mathrm{I}(1)$ \\
\hline الاستثمار الاجنبي & $-9.224815^{*}$ & $-11.02907^{*}$ & $-9.126589^{*}$ & $\mathrm{I}(1)$ \\
\hline سعر النفط & $-10.73782^{*}$ & $-10.70522^{*}$ & $-10.61590^{*}$ & $\mathrm{I}(1)$ \\
\hline الناتج المحلي الاجهالي & $-15.34056^{*}$ & $-15.168345^{*}$ & $-2.900070^{*}$ & $\mathrm{I}(1)$ \\
\hline معدل التضخم & $-9.511725^{*}$ & $-9.499422^{*}$ & $-8.392276^{*}$ & $\mathrm{I}(1)$ \\
\hline
\end{tabular}

المصدر: اعداد الباحثة بالاعتماد على برنامج 8 .Eviews.

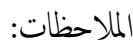

ADF -

- - علامة * تشير الى رفظ فرضية العدم من عدم الاستقرار عند مستوى معنوية

- - مول الفترة المثالية لاختبار ديكي فولر المعدل يتم تحديدها بشكل اوتوماتيكي

$$
\text { بالاعتاد على طريقة معيار أكيكي للمعلومات (AIC). }
$$

- - القيم تكون على أساس ماكينون بجانب واحد (MacKinnon, 1996).
جذر الوحدة ديكي فولر المعدل (ADF) واختبار فيليب بيرون (PP) واختبارات النكامل المشترك (Engle \& Granger, 1987) للتعرف على العلاقة الحتيقية بين متغيرات الاقتصاد الكلي ومعدلات البطلالة عندما تكون متغيرات السلاسل الزمنية الاساسية متكاملة من نفس الدرجة، ومن ثخ تحليل العلاقة باستخدم منهجية كرانجر السبية عن طريق برنامج البرنامج الاحصائي Eviews8 لمشاهدات السلسلة الزمنية السنوية لمنغيرات الدراسة وتضمن (14) مشاهدة سنوية وبالشكل الاتي:

1.4.4 اختبار جذر الوحدة (Unit Root Test) أن الجدول (3) يوضح نتاجُ اختبار ديكي فولر المعدل (ADF) عند المستوى، وبما أن القيمة الإحصائية في هذا الاختبار أكبر من القيمة الحرجة، وأيضاً كانت القيمة المعنوية أقل من قيمة ألفا (5\%)، يعني ذلك رفض فرضية العدم نتيجة وجود جذر الوحدة أي أن السلسلة الزمنية غير ساكنة عند المستوى أي عند القيمة الاصلية وأصبحت ساكنة عند أخذ الفرق الأول كما موضح في الجدول (4)، وهذا يعني بأن

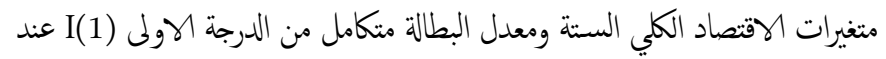
حد ثابت واتجاه أو حد ثابت فقط أو بغياب الثابت والاتجاه نتيجة رفض فرضية العدم بوجود جذر الوحدة عند أخذ الفرق الأول حيث أصبحت السلسلة ساكنة، Basher et al, 2012; ) وهذه النتأُج جاءت بالتوافق مع الدراسات السابقة Chen 2010; Elder \& Serletis, 2010; Kilian \& park 2009; Masih .(et al, 2011

\begin{tabular}{|c|c|c|c|}
\hline \multirow[b]{2}{*}{ 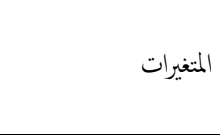 } & \multirow[b]{2}{*}{ ثابت } & \multicolumn{2}{|c|}{ اختبار ديكي فولر المعدل عند المستوى } \\
\hline & & ثابت واتجاه & واتجاه \\
\hline معدل البطالة & -1.317147 & -2.830509 & 1.975584 \\
\hline عرض النقد & -0.864954 & -4.586233 & 3.781283 \\
\hline الاتفاق & -3.808062 & -3.219181 & -1.419630 \\
\hline الاستثمار الاجنبي المباشر & -2.543047 & -4.035659 & -1.454434 \\
\hline سعر النفط & -0.964960 & -3.025690 & 1.152676 \\
\hline الناتج المحلي الاججلي & -3.292231 & -3.040600 & 1.907614 \\
\hline معدل التضخم & -0.162242 & -2.484193 & 3.789881 \\
\hline
\end{tabular}
جدول 3

المصدر: اعداد الباحثة بالاعتاد على برنامج 8. 


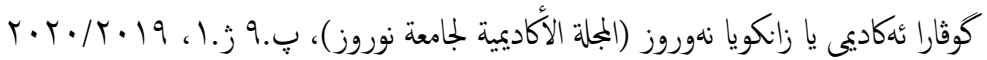

\begin{tabular}{|c|c|c|c|}
\hline المباشتثر الاجبني & $-17.72508^{*}$ & $-18.10095^{*}$ & $-17.62854^{*}$ \\
\hline سعر النفط & $-10.73722^{*}$ & $-10.70419^{*}$ & $-10.67499^{*}$ \\
\hline الناجت الملي الو. & $-24.03764^{*}$ & $-27.28956^{*}$ & $-25.64835^{*}$ \\
\hline معدل التضخم & $-9.516234^{*}$ & $-9.498259^{*}$ & $-8.485287^{*}$ \\
\hline
\end{tabular}

المصدر: اعداد الباحثة بالاعتاد على برنامج 8.516234 .4 .0

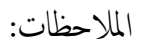
هP -

- - علامة * تشير الى رفظ فرضية العدم من عدم الاستقرار عند مستوى معنوية

- - مول الفترة المثالية لاختبار فيليب بيرون (PP) يتم تحديدها بشكل اوتوماتيكي بالاعتاد على طريقة نيوى ويست المقدم من قبل بارليت كيميل.

- القيم تكون على أساس ماكيننون بجانب واحد (MacKinnon, 1996).

\subsection{4 اختبار النكامل المشترك (Cointegration Test)}

إن الخطوة الثانية بعد اختبار جذر الوحدة تتمثل في البدء بعملية إثبات وجود علاقة طوياة الاجل بين المتغيرات من أجل تحديد فترة الابطاء الأمثل للموذج للتحقق من أن البقايا المقدرة (حد الخطأ) ليست مرتبطة بشكل تلقائي، والتي عادة ينتج عنها عن تشوه الأخطاء نتيجة كون حد الخطأ مرتبط تلقائيًا ( Lutkepohl، 2005). استخدمت هذه الدراسة اختبار النكامل المشترك بطريقة جوهانسن وجيسليوس لتفوقها على الاختبارات الاخرى وافضلية (Johansen \& Juselius Test) استخداها حيث يعتمد طريقة جوهانسون للتكامل المشترك عن نتيجة اختبار الأثر ( $\lambda$ trace $)$ أكبر من القيمة الجدولية فيتم رفض فرضية العدم بعدم وجود تكامل مشترك بين متغيرات الدراسة (H0: r = مكانت معنوية عند مستوى (5\%)، وبالتالي قبول الفرضية البديلة بوجود على الاقل تكلمل مشترك واحد (H1: r 0 0)، والجدول

$$
\text { (7) يوضح ننائُ اختبار النكلمل المشترك وبالشكل الاتي. }
$$

\begin{tabular}{|c|c|c|c|c|}
\hline & & \multicolumn{3}{|c|}{ قيمة معامل الاثر لاختبار جوهانسن وجيسليوس } \\
\hline Hypothesized & & Trace & 0.05 & \\
\hline No. of $\mathrm{CE}(\mathrm{s})$ & Eigenvalue & Statistic & Critical Value & Prob. $^{* *}$ \\
\hline None * & 0.998920 & 327.3403 & 125.6154 & 0.0000 \\
\hline At most $1^{*}$ & 0.963863 & 177.0581 & 95.75366 & 0.0000 \\
\hline At most $2 *$ & 0.904643 & 104.0082 & 69.81889 & 0.0000 \\
\hline At most $3^{*}$ & 0.770218 & 52.30529 & 47.85613 & 0.0180 \\
\hline At most 4 & 0.399108 & 19.95156 & 29.79707 & 0.4261 \\
\hline
\end{tabular}

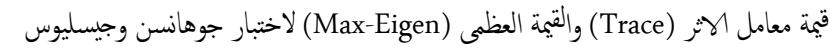

أن الجدول (5) تثثل نتائج اختبار فيليب بيرون (PP) عند المستوى، وبما أن القيمة الإحصائية في هذا الاختبار أكبر من القيمة الحرجة، وأيضاً كانت القيمة المعنوية أقل من قيمة ألفا (5\%)، يعني ذلك رضض فرضية العدم نتيجة وجود جذر الوحدة أي أن السلسلة الزمنية غير ساكنة عند المستوى أي عند القيمة الاصلية وأصبحت ساكنة عند أخذ الفرق الأول كما في الجدول (6)، وهذا يعني بأن متغيرات الاقتصاد الكلي الستة ومعدل البطالة متكمل من الدرجة الوولى I(1) عند حد ثابت واتجاه أو حد ثابت فقط أو بغياب الثابت والاتجاه نتيجة رفض فرضية العدم بوجود جذر الوحدة عند أخذ الفرق الأول حيث أصبحت السلسلة ساكنة، وهذه النتائُ جاءت للتاكد من نتائج الاختبار السابق المثتمل في اختبار ديكي فولر المعدل.

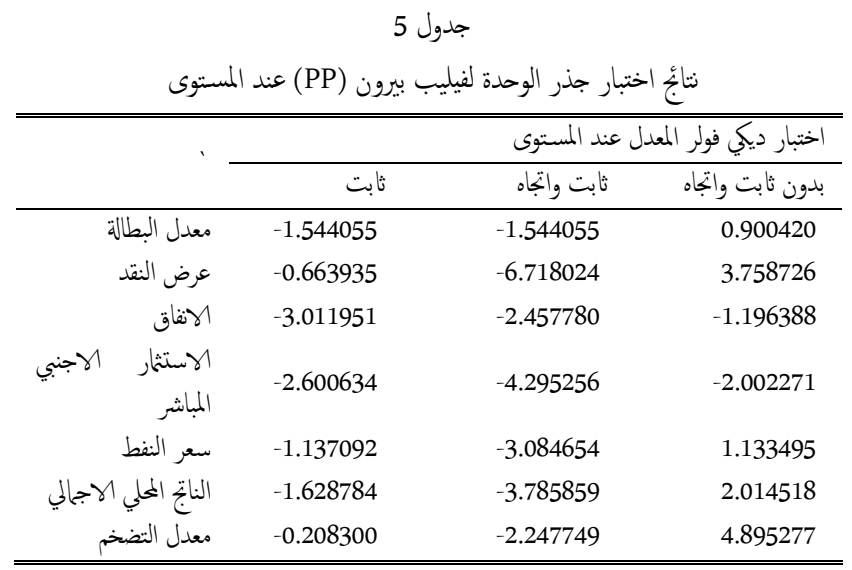

المصدر: اعداد الباحثة بالاعتماد على برنامج 8 لتضخ 8.208300.

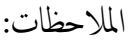
هP - - - علامة * تشير الى رفظ فرضية العدم من عدم الاستقرار عند مستوى معنوية .$\% 5$

- - مول الفترة المثالية لاختبار فيليب بيرون (PP) يتم تحديدها بشكل اوتوماتيكي بالاعتاد على طريقة نيوى ويست المقدم من قبل بارليت كيميل.

- القيم تكون على أساس ماكيننون بجانب واحد (MacKinnon, 1996). جدول 6

\begin{tabular}{|c|c|c|c|c|}
\hline \multirow{2}{*}{ المتغيرات } & \multicolumn{3}{|c|}{ اختبار ديكي فولر المعدل عند الفرق الاول } & \multirow{2}{*}{ الاستنتاج } \\
\hline & ثابت & ثابت واتجاه & بدون ثابت واتجاه & \\
\hline معدل البطالة & $-10.84769^{*}$ & $-10.82659^{*}$ & $-10.85612^{*}$ & $\mathrm{I}(1)$ \\
\hline عرض النقد & $-14.96150^{*}$ & $-14.71639^{*}$ & $-10.95989^{*}$ & $\mathrm{I}(1)$ \\
\hline الانفاق & $-9.478079^{*}$ & $-9.718703^{*}$ & $-9.461011^{*}$ & $\mathrm{I}(1)$ \\
\hline
\end{tabular}

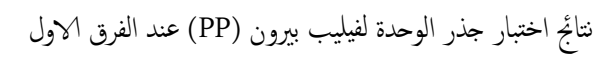




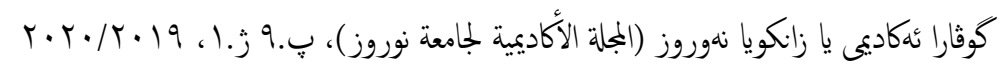

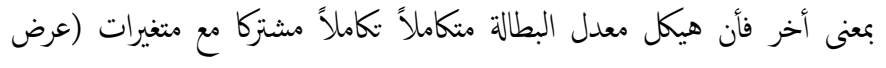
النقد، الانفاق، الاستثمار الاجنبي المباشر، أسعار النفط، الناتج المحلي الاجلالي ومعدل التضخم)، أي أن هذا الاستنناج يعني بوجود توليفة خطية ساكنة بين المبني

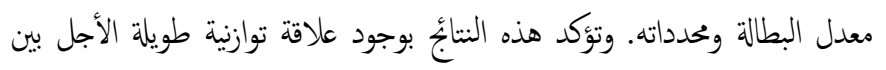

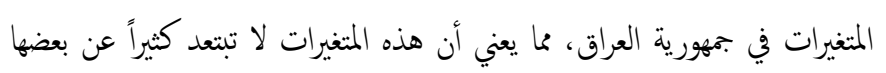

\section{البعض في الأجل الطويل بحيث تظهر سلوكاً متشاها.}

3.4.4 اختبار كرانجر اللعلاقة السبية

يستخدم اختبار كرانجر السبية لتحديد العلاقة السبية والتعرف فيها اذاكان هناك اتجاه واحد او اتجاهين او عدم وجود اي اتجاه للمتغيرات قيد الدراسة، وان وجود

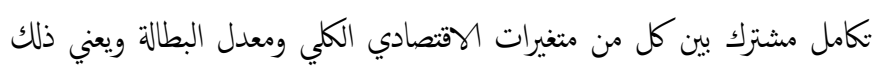
وجود علاقة توازنية طويلة الاجل بين المتغيرات حسب نتائج اختبار النكلمل المشترك لجوهانسن وجيسليوس يعني عدم وجود علاقة سبية (Causality) بين المتغبرين وبالتالي فان أي انحراف عن مسار العلاقة التوازنية على المدى البعيد سيتم

تصحيحها.

يوضح نتائج اختبار كرانجر السبية للجمهورية العراقية في الجدول (8) بادخال فترات الابطاء الختلفة، وتبين بعدم وجود علاقة سببية بين متغيرات الاقتصادي الكلي ومعدل البطالة وبذلك فان اي تغير في متغيرات الاقتصادي الكلي لا يؤدي أو لا يسبب الى التغير في معدل البطالة كون مستوى المعنوية أكبر من (5\%) لـ كاي2، إلا في حالة كون وجود علاقة سبية باتجاهين بين الناتج المحلي الاجلالي ومعدل

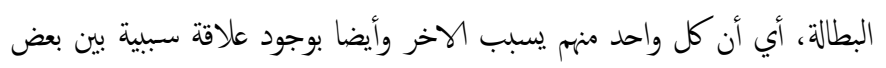
المتغيرات باتجاه واحد من البطالة الى التضخم أي أن البطالة تسبب التضخم، وهذا

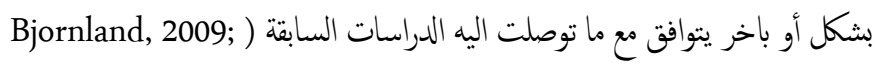
Hammoudeh \& Li, 2005; Anoruo \& Mustafa, 2007; Miller \& (Ratti, 200 يسبب في تغير معدل البطالة عند فترات الابطاء المختلفة، وأيضا نقبل فرضية العدم بان تغير معدل البطالة لا يسبب اي تغير في متغيرات الاقتصاد الكلي عند فترات الابطاء المختلفة أي لا يوجد علاقة سبية في الاتجاهين ما عدا حالة المؤشرات الحتقية. وقد تكون هذه النتائُ بسبب اعتاد الاقتصاد العراقي على إيرادات النفط

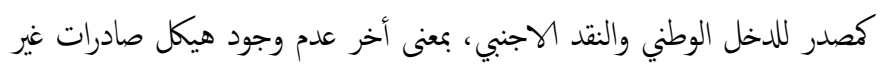
نفطية وكان متوسط نسبة أجالي الصادرات النفطية الى أجلالي الصادرات العراقية

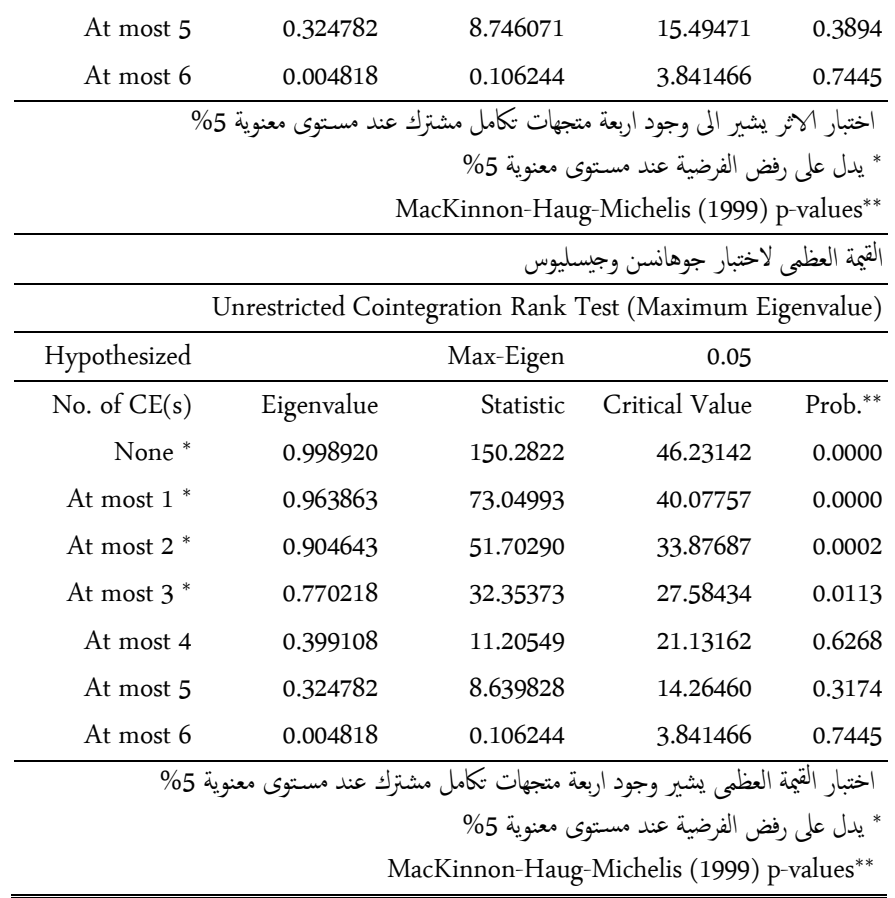

المصدر: الجدول من اعداد الباحثة بالاعتاد على خرجات برنامج Eview8

يتضح من الجدول (7) بان نتائُ اختبار جوهانسن وجيسليوس من قيمة معامل الاثر

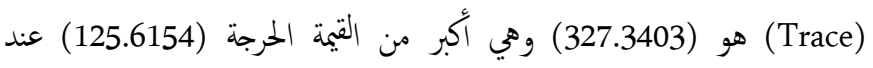
مستوى معنوية اقل من (5\%)، وتستنج بأنه يوجد نكامل مشترك وأن عدد متجهات النكامل المشترك تساوي أربعة (r=4) عند مستوى معنوية 1\% باستخدام اختبار الأثر. ويتضح من الجدول (7) بان القيمة العظى (Max-Eigen) هي (150.2822) أكبر من القيمة الحرجة (46.23142) عند مستوى معنوية أقل من (5\%)، وهذا يعني بوجود تكامل مشترك بين كل من متغيرات الاقتصاد الكلي قيد الدراسة ومعدلات البطالة، وبمعنى اخر وجود علاقة توازنية طويلة الاجل بين المتغيرات اي انها لا يتباعدان عن بعضها البعض، يعني أن أي انخفاض أو ارتفاع لأحدها يؤدي الى انخفاض او ارتفاع الاخر ، وبذلك نرفض فرضية العدم، ونستنج بأنه يوجد تكامل مشترك وأن عدد متجهات التكامل المشترك تساوي أربعة. وبالتالي يوجد حاجة لاستخدام نموذج تصحيح الخطأ الذي هيتم بالعلاقات التوازنية القصيرة الاجل نتيجة وجود علاقة النكامل المشترك بين المتغيرات وهذه النتأُ

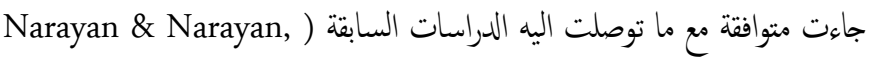
2010; Bjornland, 2009; Hammoudeh \& Li, 2005; Anoruo \& بينا تعارض هذه الدراسة مع ننائُ (Mustafa, 2007; Miller \& Ratti, 2009 الدراسة التي اجريت في ايران ( Oskooe, 2011) واندنوسيا ( Agusman \& (Boyer \& Filion, 2009) وكندا (Deriantino, 2008 


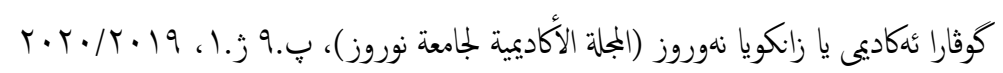

بالإضافة إلى ذلك، تم تأكيد مثانة النموذج من خلال الاختبارات التشخيصية المتعلقة بالتوزيع الطبيعي الطبيعية، الارتباط التسلسلي، تجانس التباين والاستقرار الهيكلي للمنوذج، وعممًا النموذج قد اجتاز جميع الاختبارات التشخيصية. يوضح الجداول الخاصة بتقييم النموذج أنه لا يوجد دليل على الارتباط الذاتي للبواقي، ويتبع التوزيع

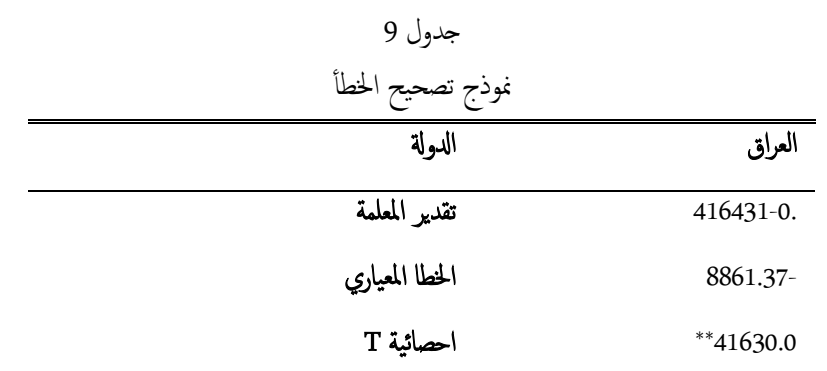

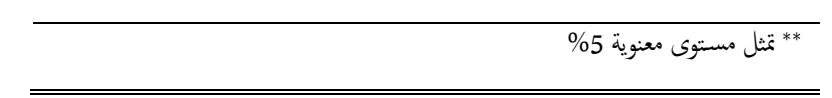

ولكون قيمة المتغير الوهمي (تواجد داعش) للفتزة (2013-2017) كانت غير معنوية ومعامل التحديد كان بالاشارة السالبة، فذلك يعني بان تواجد داعش ليس لدهيا تأثير على المتغير المعتمد بالنسبة لمههورية العراق، وبالتالي فان فترة تواجد داعش لم تؤثر على معدل البطالة وقد يكون سبب ذلك الفترة الزمنية القليلة التي تواجد فيها تنظيم داعش في العراق ، والتي لم تظهر تاثيرا على المدى الطويل في التحليل القياسي للمنوذج وهذه النتائُ جاءت متوافقة مع الدراسات السابقة ( Dacloush, 2013)(أسعد، 2014) وكما يوضحه الجدول (10). جدول 10 نتائج الفرضيات

\begin{tabular}{|c|c|c|c|c|}
\hline الفرضية الرابعة & الفرضية الثالثة & الفرضية الثانية & الفرضية الوولى & الدول \\
\hline قبول العدم & جزئي البدياة / & قبول البدياة & 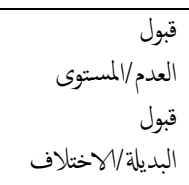 & العهروية \\
\hline $\begin{array}{r}\text { الصغرية المربعات } \\
\text { (OLS) }\end{array}$ & اللعلاقة السبية كرانج & 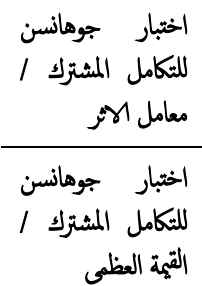 & المعتلار ديكي فولر & المستخدارات \\
\hline
\end{tabular}

المصدر: من إعداد الباحثة بالاعتاد على نتائج الاختبارات المختلفة.
وصل الى (99.60648) للفترة (2014-2009) )

.(Bulletin, 2014, 14-20

$$
\begin{aligned}
& \text { جدول } 8 \\
& \text { اختبار بيروايس كرانجر السببية }
\end{aligned}
$$

Date: 04/18/19 Time: 04:51

Sample: 20042017

Lags: 2

\begin{tabular}{lccl}
\hline Null Hypothesis: & Obs & F-Statistic & Prob. \\
\hline M1 does not Granger Cause UNE & 12 & 1.45180 & 0.2969 \\
UNE does not Granger Cause M1 & & 1.90622 & 0.2183 \\
\hline EX does not Granger Cause UNE & 12 & 0.00640 & 0.9936 \\
UNE does not Granger Cause EX & & 2.29560 & 0.1712 \\
\hline FDI does not Granger Cause UNE & 12 & 0.06328 & 0.9392 \\
UNE does not Granger Cause FDI & & 0.41434 & 0.6760 \\
\hline OP does not Granger Cause UNE & 12 & 0.15032 & 0.8631 \\
UNE does not Granger Cause OP & & 0.29929 & 0.7504 \\
\hline GDP does not Granger Cause UNE & 12 & 3.14201 & 0.0490 \\
UNE does not Granger Cause GDP & & 3.34515 & 0.0496 \\
\hline INF does not Granger Cause UNE & 12 & 0.11432 & 0.8927 \\
UNE does not Granger Cause INF & & 3.32796 & 0.0303 \\
\hline \hline
\end{tabular}

المصدر: الجدول من اعداد الباحثة بالاعتاد على خرجات برنامج Eview8

\subsection{4 نموذج تصحيح الخطأ}

إن نموذج تصحيح الخطأ يدل على سرعة التكيف من الأجل القصير إلى التوازن في الأجل الطويل بحيث يقيس سرعة تكيف الاختلالات في الأجل القصير الى التوازن طويل الأجل، بمعنى أخرى يشير إلى مقدار التغير في المتغير النابع نتيجة لانحراف قيمة المتغير المستقل في الأجل القصير عن قيمنه التوازنية في الأجل الطويل بمقدار وحدة واحدة. إن وجود علاقة طوية الأمد بين هذه المتغيرات في النموذج، فان تقدير تصحيح الأخطاء في المدى القصير موضح في الجدول (9). أن معنوية معلمة تصحيح الخطأ هو دليل آخر على وجود علاقة مستقرة طويلة الأجل، وأيضاً فأن العلامة السلبية المتوقعة لنموذج تصحيح الخطأ هي ضرورية في النموذج، وذلك يؤكد مرة أخرى وجود علاقة النكمل المشترك بين متغيرات هذا النموذج (Bannerjee, et at., 1998)، وأن المعامل المقدر لتصحيح الخطأ هو (11.6 \%) وذات مستوى معنوية عند (5\%)، مقترها بأنه يتم تصحيح عدم التوازن في الفتزة الأخيرة (السنة) في معدلات البطالة في السنة للعراق المقبلة بنسبة (11.6٪) فقط، ويبدو أن هذه التمة تتكيف ببطء نحو التوازن على المدى الطويل. 


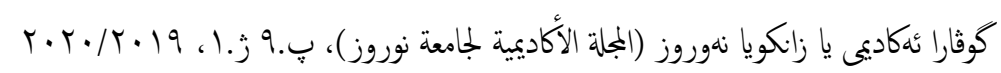

اختبار ديكي فولر المعدل وفيليب فيرون ، وهذا يؤكد تطابق السلاسل الزمنية في العراق مع نظيراتها في مجموعة البلدان النامية .

نستنتج بأن هناك تكامل مشترك أي المتغيرات مرتبطة ببعضها البعض في المدى الطويل، أي أن هيكل معدل البطالة متكملاً تكاملاً مشتركا مع متغير (عرض النقد، الانفاق، الاستثمار الاجنبي المباشر، أسعار النفط، الناتج المحلي الاجلالي ومعدل التضخم)، وهذا يعني بوجود توليفة خطية ساكنة بين معدل البطالة ومحدداته في العراق ، والسبب هو ان اقتصاد العراق هو اقتصاد ريعي

يستنج من خلال اختبار كزخر العلاقة السبية ذو اتجاهين بين البطالة الناتج المحلي الاجالي، بينا ذو اتجاه واحد من البطالة أي أن البطالة هي تقود معدل التضخم في العراق، وعدم وجود العلاقة السبية لبقية المتغيرات الاخرى مع البطالة.

يستنتج بأن قيمة المتغير الوهي (تواجد داعش) للفترة (2013-2017) كان غير معنويا ومعامل التحديد كان بالاشارة السالبة، فذلك يعني بان تواجد داعش ليس لدهيا تأثير على معدل البطالة في العراق اذ ان فتزة تواجد التنظيم لم تدم طويلا ، وبذلك كان اثرها محدود على السلسلة الزمنية لبيانات العراق.

2.5 المتترحات

تقتزح الدراسة قيام الدولة بالتدخل المباشر الفعال في معالجة المشاكل الهيكلية للاقتصاد العراقي وبناء شراكة وتحالف حقيقي مع القطاع الخاص عن طريق مراجعة وتعديل الكثير من القوانين وسياسات العراق الاقتصادية والمالية لتنويع مصادر التمويل وعدم الاعتماد على النفط فقط بشكل يساهم في تقليل البطالة واحتواء العدد الكبير من الخزييين من الشباب ودمجهم مع سوق العمل.

ضرورة استغلال الايرادات النفطية في خدمة الاستثار في مشاريع التنمية المستدامة وتحسين نوعية تقديم الخدمات العامة وخاصة في دع وتشجيع القطاعات الاساسية منها الزراعة والصناعة والسياحة من خلال توفير المستلزمات الضرورية لتشغيل تلك القطاعات من أجل استقطاب وجذب رتب قوة العمل العاطلة ومن ثم تخفيض معدلات البطالة.
بناءً على الإطار النظري والدراسات السابقة التي تم عرضها ونتائج الجانب التطبيقي، فقد توصلت هذه الدراسة إلى جملة من الاستنتاجات والمقترحات وكلالتي:

1.5 الاستنتاجات

يعتبر معدل البطالة احد اهم المؤشرات الاقتصادية الكلية التي يتم الاعتلاد عليها في رسم السياسات الاقتصادية وتقييم كفاءتها، ولا يكن بيان حجم واثار وابعاد البطالة دون حساب معدل البطالة ( نسبة الافراد العاطلين الى قوة

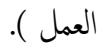
إن الاقتصاد العراقي لم يعاني من مشكلة البطالة في سبعينات وثمانينات القرن الماضي حيث لم يتجاوز النسبة أربعة بالمئة من إجالي قوة العمل والتي كانت مقبولة اقتصادياً بعكس ما يعانية اقتصاديات الدول من مشكلة البطالة ومنها العراق كما تم ذكه من قبل الجهاز المركزي للإحصاء العراقي بان نسبة البطالة بين الشباب في العراق تجاوز 22\%، في حين أعلن صندوق النقد الدولي في أيار 2018 بأن معدل البطالة للشباب في العراق تجاوز 40\%. ان نتاجُ الدراسات السابقة مازالت غير واضحة وغير متفقة في تقديم دليل محدد حول اتجاه العلاقة والتثاثير بين معدلات البطالة ومتغيرات الاقتصاد الكلي سواء في الدول المتقدمة او النامية وبذلك أتاحت الفرصة للباحثين لاجراء المزيد من الدراسات.

إن العراق شهد تراجعا كبيرا في جذب رؤوس الأموال وانخفاض معدلات النمو وزيادة معدلات البطالة بسبب جملة من العوامل الاقتصادية والاجتاعية والسياسية والاسباب الامنية والفساد الاداري والمالي ما انغكس سلبا على رك بمحل الانشطة الاقتصادية ، وأن البيئة العراقية هي طاردة وليست جاذبة للاستثمر الاجنبي المباشر نتيجة العوامل السابقة وبالمصصة فان معدلات البطالة تتجه الى الارتفاع.

إن السلسلة الزمنية للدراسة غير ساكنة عند المستوى أي عند القيمة الاصلية وأصبحت ساكنة عند أخذ الفرق الأول وبالتالي يتم رفض فرضية العدم لوجود جذر الوحدة ومن ثم أصبحت ساكنة عند أخذ الفرق الأول أي أن متغيرات الاقتصاد الكلي الستة ومعدل البطالة متكلمل من الدرجة الاولى (1) عند حد ثابت واتجاه أو حد ثابت فقط أو بغياب الثابت والاتجاه باستخدام 


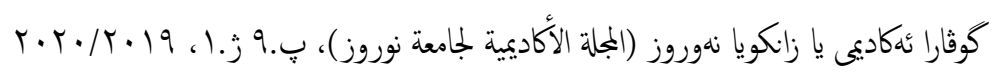

1. Arestis, P., Demetriades, P., \& Luintel, K. (2001). Financial development and economic growth: The role of stock markets. Journal of Money, Credit and Banking, 33.

2. Arouri, M.E., \& Rault, C. (2009). Oil prices and stock markets: what drives what in the Gulf Corporation Council countries?, Working Paper Number 960, 6-2009, William Davidson Institute.

3. Awan, M. Z., Uz-Zaman, K., \& Khan, B. (2010). Determinants of foreign direct investment in services sector of Pakistan: An econometric approach. Global Financial Crisis: Causes, Emerging Trends and Strategy, 5(2).

4. Basher, S.A., Haug, A.A., \& Sadorsky, P. (2012). Oil prices, exchange rates and emerging stock markets. Energy Economics, 34, 227-240.

5. Banerjee, A., Dolado, J. J., \& Mestre, R. (1998). Error-correction mechanism tests for cointegration in a single-equation framework. Journal of Time Series Analysis, 19.

6. Berk, I., \& Aydogan, B. (2012). Crude oil price shocks and stock return: Evidence from Turkish stock market under global liquidity conditions. EWI working papers. BP statistical review of world energy, June 2012 (www.BP.com).

7. Bjørnland, H.C. (2009). Oil price shocks and stock market booms in an oil-exporting country. Scottish Journal of Political Economy, 56.

8. Creti, A., Ftiti, Z., \& Guesmi, K. (2013). Oil price impact on financial markets: co-spectral analysis for exporting versus importing countries. EconomiX Working Papers 2013-11, University of Paris West.

9. Engle, R. F., \& Granger, C. W. J. (1987). Cointegration and error correction: Representation estimation and testing. Econometrica, 55 .

10. Eryigit, M. (2009). Effects of Oil Price Changes on the Sector Indices of Istanbul Stock Exchange. International Research Journal of Finance and Economics, 25.

11. Hammoudeh, S., \& Choi, K. (2006). Behavior of GCC stock markets and impacts of US oil and financial markets. Research in International Business and Finance, 20.

12. Lutkepohl, H. (2005). New introduction to multiple times series analysis. (2ed Ed.), Springer, Berlin.

13. Mashayekh, S., Moradkhani, H. H., \& Jafari, M. (2011). Impact of macroeconomic variables on stock market: The case of Iran. Paper presented at the Second International Conference on Business and Economic Research.
ضرورة اعادة الهيكة للقطاع الحكومي للسيطرة على البطالة المقنعة من خلال قيام الوزرات بتحديد احتياجاتها الفعلية من الايدى العاملة واعادة توزيع القوى الفائضة على الهماكن الاخرى عند الحاجة، وضرورة قيام القطاع الخاص وفضلا عن ربط القطاع المصرفي بعملية التنمية على مستوى جميع القطاعات الاقتصادية من خلال تقديم التسهيلات المناسبة من الاعفاءات الضريبية ليتسنى للمصارف بمنح قروض مصرفية بأسعار فائدة منخفضة.

توفير بيئة أمنية وسياسية مستقرة من أجل تحقيق معدل نمو اقتصادي يتناسب ويتوافق مع الزيادة الحاصلة في النمو السكاني من أجل تحقيق انخفاض في معدلات البطالة. دع وتطوير مراكز او مكاتب خاصة لتقديم المعلومات المطلوبة عن فرص العمل الموجودة باستخدام التقنيات التكنولوجية الحديثة لتقليل مشكلة البطالة من خلال تسهيل عملية تحويل الافراد من منطقة الى اخرى، وأيضاً تقدم هذه المراكز أو المكاتب إعادة تأهيل القوة العاطلة عن العمل بشكل يتناسب مع

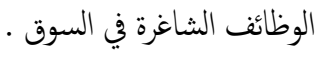

تقترح الدراسة ادخال وأضافة متغيرات أخرى كأسعار الذهب، او الحكي الرشيد أو مؤشرات الفساد في الدراسات المستتقبلية المشاهية لتحسين وتطوير التغيرات في النتائُ المتعلقة بتأثير تغيرات متغيرات الاقتصاد الكلي على معدلات البطالة، أو من الممكن اضافة متغيرات غير اقتصادية كالأخطار السياسية والإرهاب والفساد والانتخابات وتوتز العلاقة بين المركز واقليم كردستان وغرها، وكلها عوامل تؤثر على ثقة المستتمر والشركات والقرارات الحكومية.

اجراء المزيد من الدراسات لمعرفة الاسباب وراء ارتفاع معدلات البطالة وتدني تدفقات الاستثمر الاجنبي المباشر الى العراق مقارنة مع منطقة الثرق الاوسط وشمال افريقيا وخاصة تدني ترتبب العراق في المؤشرات التنمية والاستثمر وسهولة الاعمال. 6. قامُة المصادر 


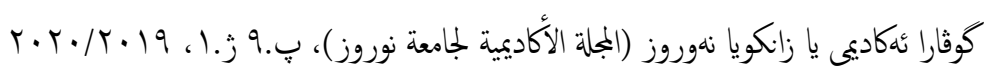

32. عقون ، سليم (2010 )، قياس اثر المتغيرات الاقتصادية الكلية على معدل البطالة دراسة تحليلية قياسية - حالة الجزائر ، رسالة ماجستير ، كلية العلوم الاقتصادية وعلوم

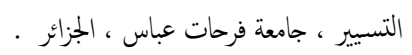

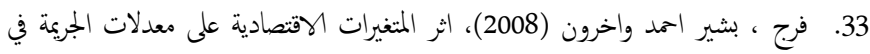

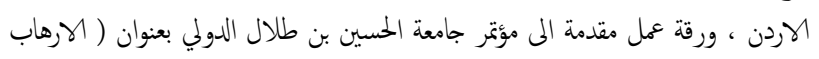

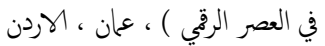
34. عمر ، معن خليل عمر والعاني ،عبد اللطيف (1991)،المشكلات الاجتماعية،وزارة التعليم العالي والبحث العلمي،جامعة بغداد . 35. علي ، عبد المنعم السيد (1984 ) ـ اقتصادات النقود والمصارف في النظم الرأسمالية والأشتراكية والأقطار النامية مع أشارة خاصة للعراق . ( بغداد : مطبعة جامعة الموصل الجزء الأول . 36. عمر ، بيار محدرشيد. (2017). أثر أسعار النفط على سوق العراق للأوراق المالية للفتزة (2014-2010): دراسة تطبيقية 37. مجلخ ،سليم (2016 ) محددات البطالة في الجزائر دراسة تطبيقية ، مجلة جامعة الشارقة ،

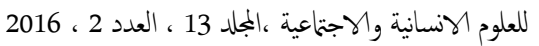
38. محمد الأمين، كماسي و عبد الغاني ، دادن ( 2002 )، تحليل النفقات في الميزانية العامة الماني

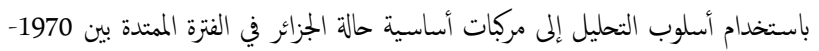
2000، بجلة الباحث، عدد 01 . 39. مرعاني وأسعد، بيار محرشيد وزيرفان عبدالمسسن. (2014أ). تحليل قدرة المصارف العاملة .

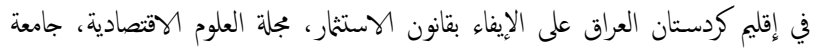

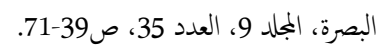
40. ناصر ، قاسمي (1992) ،خريجو الجامعة وسوق العمل ، رسالة ماجستير ، معهد علم الاجتماع ، جامعة الجزائر.

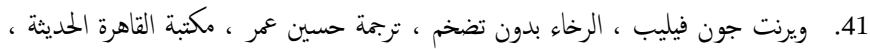
القاهرة ، مصر من فئس

14. Miller, J.I., \& Ratti, R.A. (2009). Crude oil and stock markets: Stability, instability and bubbles. Energy Economics, 31, 559-568.

15. Oskenbayev, Y., Yilmaz, M., \& Chagirov, D. (2011). The impact of macroeconomic indicators on stock exchange performance in Kazakhstan. African Journal of Business Management, 5(7).

16. Samuelson, Paul “Economics" New York, Mc Graw-Atill Book co, 1977

17. Vuyyuri, S. (2005). Relationship between real and financial variables in India: A cointegration analysis, accessed on November 20, 2008, [available at http://ssrn.com/abstract=711541].

18. Wongbangpo, P., \& Sharma, S. C. (2002). Stock market and macroeconomic fundamental dynamic interactions: ASEAN-5 countries. Journal of Asian Economics, 13(2) .

19. Johansen, S., \& Juselius, K. (1990). Maximum likelihood estimation and inference on cointegration with applications to the demand for money. Oxford Bulletin of Economics and Statistics Journal, 52.

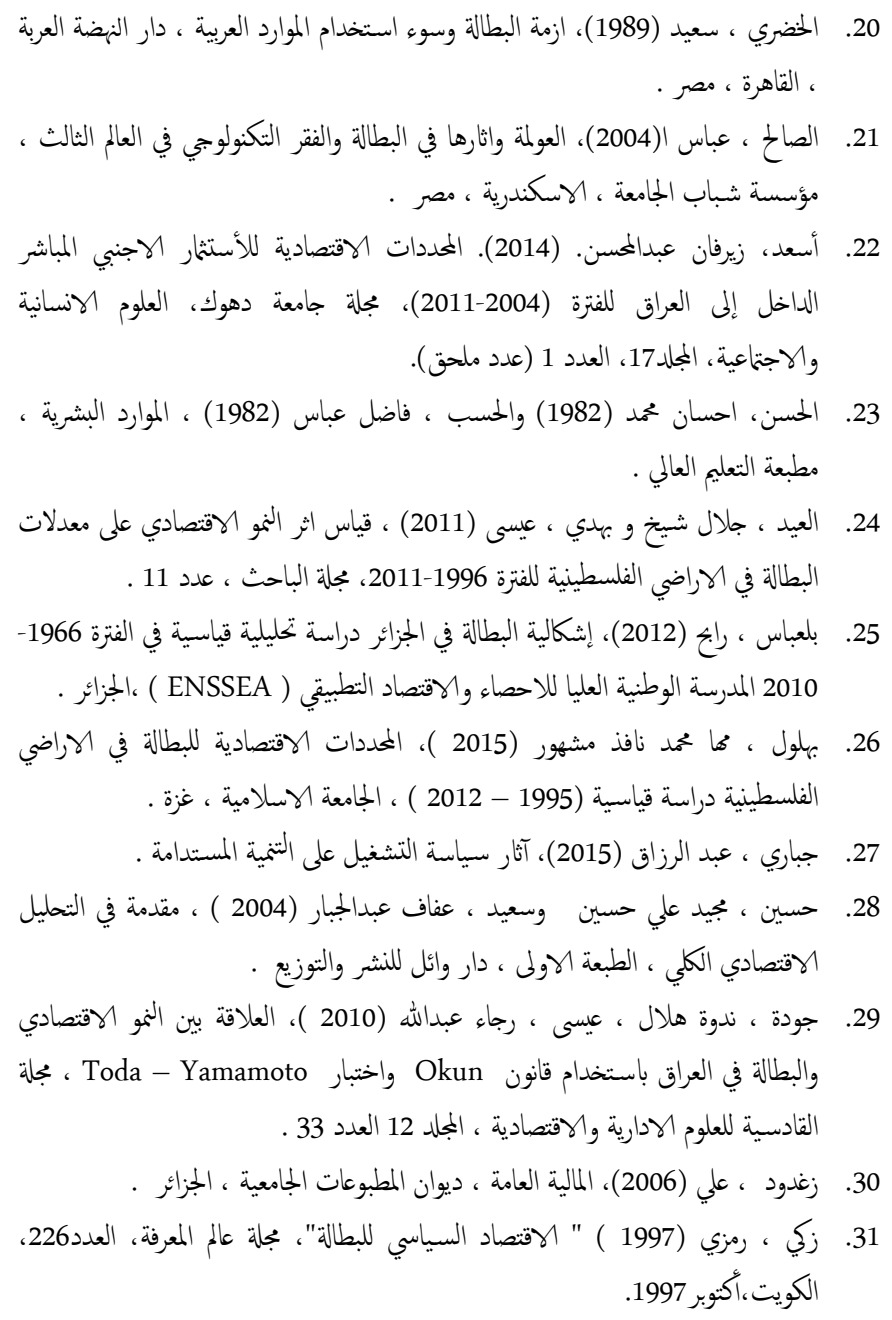

